\title{
Um sistema deposicional de planície de maré aberta, dominado por ondas: a Formação Lagarto, Ordoviciano (?), Domínio Estância, Sergipe
}

\author{
Pedro Henrique Vieira de Lucal, Giorgio Basilici² \& Elson Paiva de Oliveira ${ }^{3}$
}

\begin{abstract}
Resumo A Formação Lagarto é o registro de um sistema deposicional de planície de maré aberta em que a distribuição e deposição dos sedimentos eram controladas pela ação das ondas de tempestade e das marés. Este tipo de sistema deposicional, relativamente comum atualmente, mas pouco descrito no registro geológico, apresenta a particularidade de ser caracterizado por HCS (hummocky cross-stratifications) formadas em água rasa. Um detalhado estudo de análise de fácies foi usado para descrever as litofácies, definir uma organização arquitetural e um modelo deposicional da Formação Lagarto e para discutir os fatores de geração e preservação das $H C S$ em água rasa. Processos deposicionais produzidos por fluxos oscilatórios, unidirecionais e combinados foram reconhecidos nas sete litofácies descritas, que compõem três elementos arquiteturais. Os três elementos arquiteturais se formaram numa faixa de intermaré como indicado pelas comuns estruturas de emersão nos pelitos. A proximidade à linha de costa foi deduzida em função da distribuição da relação arenito/ pelito e da energia dos processos deposicionais. Assim, o elemento mais distal é caracterizado por grandes $H C S$ e quase ausência de pelito e o elemento mais proximal por pequenas marcas onduladas e abundância de pelito. O sistema deposicional é interpretado como uma extensa costa aberta sujeita a forte variação da maré. Nesta área, as ondas de tempestade, que progressivamente se atenuavam da parte distal à parte proximal, depositavam a maioria da areia. Ausência de ondas de tempo bom, ausência de fortes correntes de marés, ausência de organismos e alta taxa de sedimentação permitiram a preservação de $H C S$ em água rasa.
\end{abstract}

Palavras-chave: planície de maré de aberta, estratificações cruzadas de tipo hummocky, Formação Lagarto, Ordoviciano.

\begin{abstract}
A wave-dominated, open-coast tidal flat depositional system: the Lagarto Formation, Ordovician (?), Estância Domain, Sergipe. The Lagarto Formation was interpreted as a depositional system of tidal flat where storm waves and tides controlled the sedimentation. This type of depositional system, which is presently relatively common, but uncommon in the geological record, contains hummocky cross-stratifications (HCS) formed in shallow water. Detailed facies analysis was used to define the physical characteristics of the sediments, a depositional architectural organisation, a depositional model and the controlling factors that preserved HCS in shallow-water. Seven facies, formed by oscillatory, unidirectional and combined flows, were recognised. They compose three architectural elements that represent the intertidal zone of a wave-dominated, open-coast tidal flat. The most distal element is characterised by thick and spaced HCS and small amount of mudstone. On the contrary, the most proximal elements display small wave or combined ripples and a high amount of mudstone. This organisation is due to the progressive attenuation of wave and tide energy approaching to the coast. Physical, biological, and geological factors influenced the preservation of HCS in shallow-waters. Fair-weather waves and tidal currents were not able to rework the storm deposited sandstone in the intertidal area. Environmental conditions did not allow the development of a biological community that could disrupt the sedimentary structure of the HCS. High sedimentation rate has allowed the rapid burial and preservation of the HCS beds.
\end{abstract}

\section{Keywords: open-coast tidal flat, hummocky cross-stratifications, Lagarto Formation, Ordovician.}

INTRODUÇÃO O estudo de sucessões sedimentares costeiras clásticas dominadas por depósitos de tempestades constitui um alvo de interesse para a sedimentologia porque pode ser aplicado para o estudo da dinâmica dos processos de erosão, transporte e sedimentação em ambiente costeiro, assim como para a aplicação na indústria do petróleo (Davis Jr \& Fitzgerald 2004).

Apesar de vários estudos sobre as características de depósitos nas áreas costeiras dominadas por ondas, não há um consenso sobre quais são os processos determinantes para a distribuição de sedimentos nas porções que vão da costa até plataforma e de como estes processos interagem na formação dos corpos sedimentares (Cheel \& Leckie 1993). Em geral, os modelos descrevem um decréscimo da dimensão e espessura dos corpos arenosos da parte superior à parte inferior da face litorânea (shoreface) (Dott \& Bourgeois 1982; Walker 1984; Brenchley 1985; Seilacker \& Aigner 1991; Reading 1996). No entanto, al-

1 - Unicamp, Programa de Pós-graduação DEP, Campinas (SP), Brasil. E-mail: Pedro.Luca@ige.unicamp.br

2 - Unicamp, DGRN/IG, Campinas (SP), Brasil. E-mail: basilici@ige.unicamp.br

3 - Unicamp, DGRN/IG, Campinas (SP), Brasil. E-mail: elson@ige.unicamp.br 
guns modelos descrevem um aumento granulométrico e de espessura dos litossomas arenosos da parte proximal a parte distal, até a região central da face litorânea inferior, para depois diminuir de espessura novamente em direção de costa afora (Myrow 1992).

Dalrymple et al. (1992), Reading (1996) e Davis \& Fitzgerald (2004) propõem modelos costeiros baseados em ambientes cuja sedimentação é controlada por um único processo deposicional. Contudo, grande parte dos sistemas costeiros é influenciada por mais de um processo sedimentar (atividade de ondas, marés e rios) e, consequentemente, as litofácies geradas nestes sistemas possuem características mistas (Boyd et al. 1992; Dalrymple et al. 2006).

Neste contexto, a Formação Lagarto, pertencente ao Domínio Estância e localizada na porção sul da Faixa Sergipana, é um ótimo exemplo antigo para estudar a distribuição de sedimentos costeiros em ambiente dominados por processos dinâmicos mistos (ondas e marés). Saes \& Vilas Boas (1983) já interpretaram esta formação como sistema deposicional costeiro de planície de maré, antepraia e plataforma. $\mathrm{O}$ presente trabalho tem por finalidade construir um modelo de distribuição de sedimentos em áreas costeiras dominadas por ondas e marés e auxiliar no reconhecimento das principais características dos corpos geológicos a na arquitetura deposicional formados nestas áreas deposicionais.

Para conseguir este resultado foram medidas e analisadas 24 seções estratigráficas de arenitos e pelitos numa área de $400 \mathrm{~km}^{2}$ no entorno da cidade de Lagarto. Critérios de análise de fácies de detalhe foram aplicados ao estudo destes sedimentos, direcionados mais para a interpretação dos processos deposicionais que para a caracterização de modelos ou códigos de fácies (Walker 2006). Análises petrográficas de amostras de arenitos foram contempladas para a caracterização granulométrica e mineralógica dos mesmos. A elaboração dos dados levou a construção de um modelo de distribuição lateral das litofácies (trato de fácies) que visa esclarecer o modo de distribuição de sedimento numa costa aberta dominadas por marés e ondas.

CONTEXTO GEOLÓGICO A Formação Lagarto faz parte da Faixa Sergipana, situada na porção sul da Província Borborema (Fig. 1A). A Faixa Sergipana constitui uma faixa orogênica de forma triangular de direção WNW-ESE que foi desenvolvida durante o ciclo Brasiliano, em decorrência da colisão entre o Cráton São Francisco e o Maciço Pernambuco-Alagoas (Silva Filho et al. 1978a, 1978b).

A Faixa Sergipana é formada por seis domínios tectono-estratigráficos: Domínio Vaza Barris, Domínio Macururé, Domínio Marancó, Domínio Poço Redondo, Domínio Canindé e Domínio Estância (D'el-Rey Silva 1995). Estes domínios são separados por falhas de cavalgamento e de transcorrência, contendo direções aproximadas WNW-ESE, e são intersectados por bacias mesozóicas (bacias Tucano-Jatobá e Sergipe-Alagoas).

O Domínio Estância é formado por rochas sedimentares siliciclásticas e carbonáticas. Saes \& Vilas Boas
(1986; 1989), Saes (1984) e Santos et al. (1998) reconheceram quatro unidades litoestratigráficas pertencentes ao Domínio Estância, sendo elas, da base para o topo: Formação Juetê, Formação Acauã, Formação Lagarto e Formação Palmares. A Formação Lagarto é composta por alternâncias de arenitos finos e muito finos e pelitos e recobre os sedimentos carbonáticos da Formação Acauã com contato brusco e erosivo (Saes \& Vilas Boas 1989). A Formação Lagarto é interpretada por Saes \& Vilas Boas (1983) como uma sucessão terrígena formada em ambiente deposicional de planície de maré, ante-praia e plataforma.

DESCRIÇÃO DAS LITOFÁCIES A área de estudo situa-se nas proximidades da cidade de Lagarto no Estado de Sergipe (Fig. 1B). Embora os afloramentos da Formação Lagarto sejam descontínuos, o constante mergulho das camadas e a ausência de visíveis dobras e falhas levam supor que a sua espessura total na área de estudo seja aproximadamente de $1300 \mathrm{~m}$. Esta unidade é aqui composta por alternâncias de pacotes de arenitos e pelitos. Os arenitos mostram uma composição mineralógica contendo entre 61,40 e $71,88 \%$ de quartzo, 6,64 e $15,61 \%$ de feldspatos e 17,25 e $25,96 \%$ de fragmentos líticos; os clastos são entre angulares e subarredondados. Segundo a classificação de Pettijohn et al. (1987), a maioria dos arenitos é classificada como sublitarenito ou litarenito (De Luca 2008). Sete litofácies sedimentares foram reconhecidas a partir de suas características litológicas, estruturas sedimentares e da interpretação dos mecanismos deposicionais que as geraram.

Litofácies 1: arenitos com estratificação cruzada tipo hummocky acrescional (accretionary hummocky crossstratification - HCS) A litofácies 1 é constituída por camadas de arenitos de granulação medio-fina, espessas 1,5-3,4 m, e caracterizadas por topos ondulados e base plana ou ondulada (Fig. 2). A superfície superior destas camadas mostra domos de forma levemente elíptica em planta, amplitude até $0,3 \mathrm{~m}$ e espaçamento que varia de 1 a $14 \mathrm{~m}$. Os contatos superiores e inferiores das camadas são bruscos, porém não erosivos. Internamente as camadas são constituídas por lâminas aproximadamente paralelas, que possuem um leve espessamento ascendente nas porções centrais dos domos e configuram uma laminação ondulada ascendente (Fig. 3). As lâminas diminuem de espessura para cima, de $40 \mathrm{~mm}$ na base até $3 \mathrm{~mm}$ no topo. Cada lâmina é caracterizada por uma gradação normal, formada por areia médio-fina ou fina para areia muito fina (Fig. 4A). Comumente, nas porções basais, encontram-se lâminas contendo clastos intraformacionais lamosos, cujas dimensões variam de poucos milímetros até aproximadamente $100 \mathrm{~mm}$ (Fig. 4B). Acima das lâminas onduladas, se observam até dois sets de laminações cruzadas, produzidas por marcas onduladas de corrente com crista lunada (current ripples). Estes sets são sucessivamente cobertos por marcas onduladas de onda (wave ripples) com cristas retilíneas, às vezes bifurcadas (Fig. 4C). Enfim, uma lâmina delgada de pelito, que se concentra preferencialmente nas depressões formadas entre as cristas das marcas onduladas de onda e que frequente- 

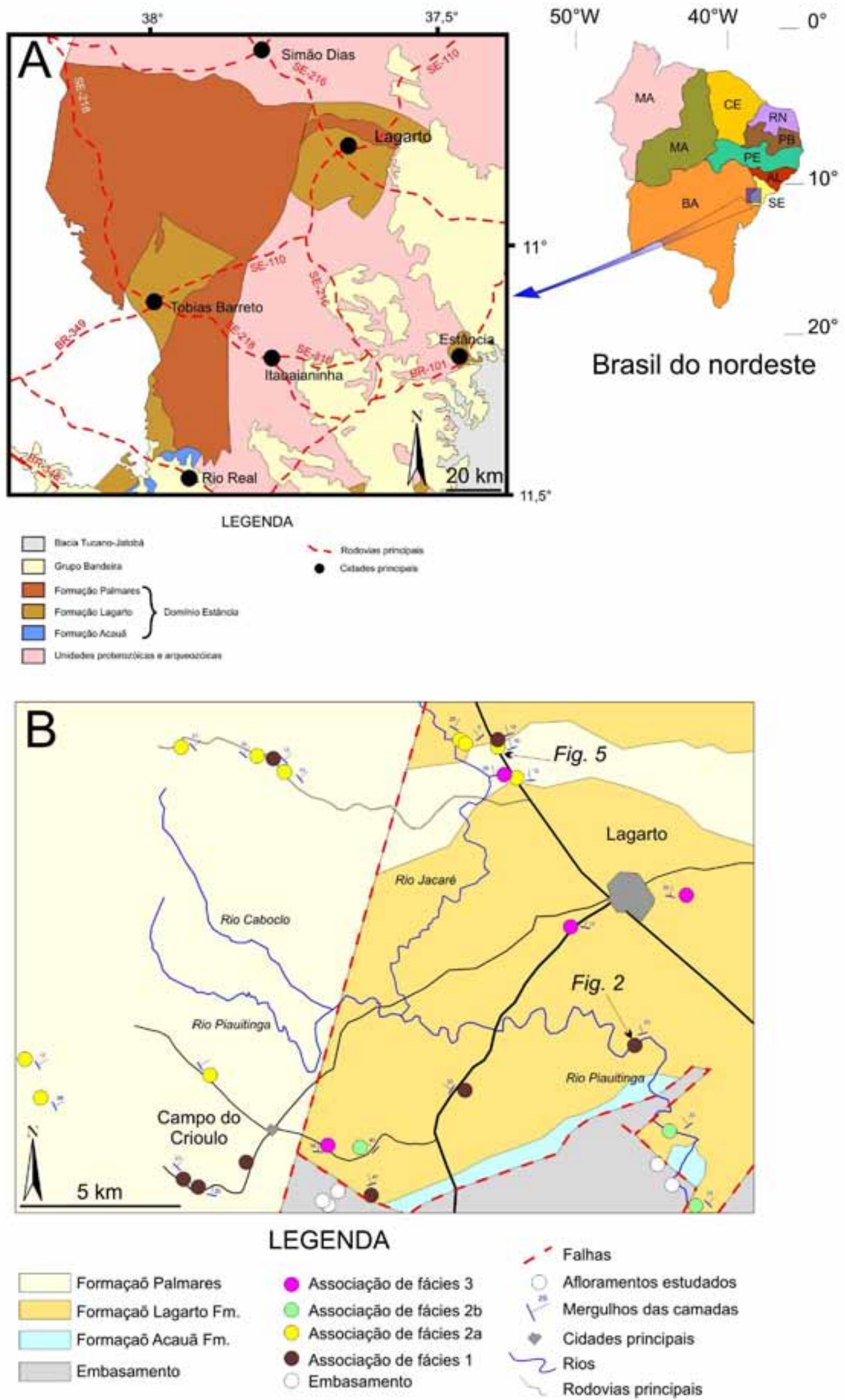

Figura $1 A$ - A área de estudo está localizada no Domínio Estância, que é o mais externo da Faixa Sergipana. B. Localização dos afloramentos estudados. 


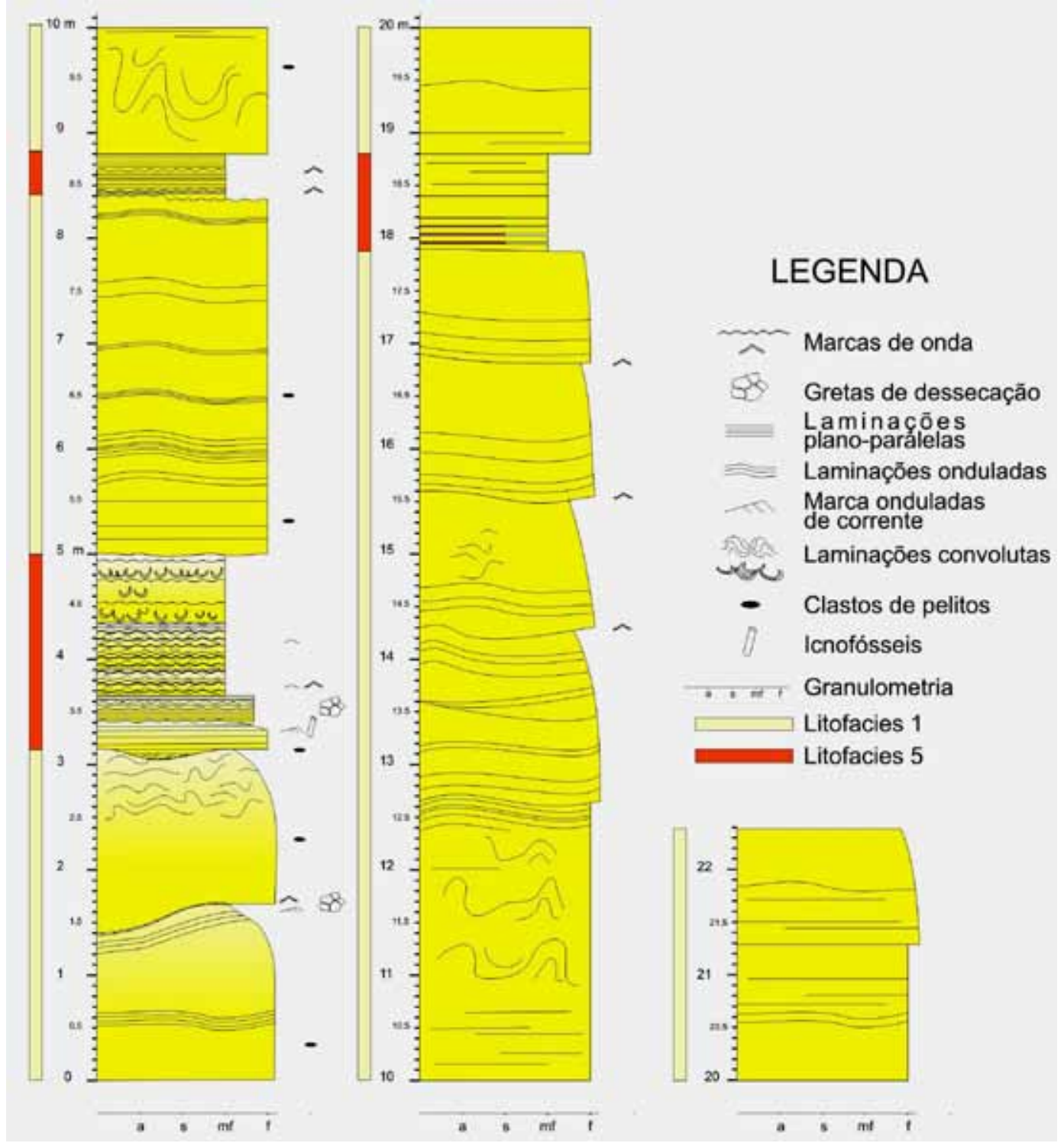

Figura 2 - Seção estratigráfica localizada a vale da represa do Rio Piauitinga, S de Lagarto (coordenadas geográficas UTM 645658/8788136). A seção representa a distribuição das litofácies 1 e 5 no elemento arquitetural 1.

mente apresenta gretas de dessecação, cobre a camada de arenito (Fig. 4D). Feições desenvolvidas por convolução, como dobras assimétricas, são comuns, alocando-se, preferencialmente, nas porções centrais das camadas.

INTERPRETAÇÃO A litofácies 1 é interpretada como hummocky cross-stratification (HCS) de tipo acrescional. Estruturas similares às da litofácies 1 foram descritas por Brenchley \& Newall (1982) e Craft \& Bridge (1987), que as atribuíram a movimentos oscilatórios das partículas de sedimento gerados por ondas de grande amplitude e espaçamento (ondas de tempestades) em condições de alta taxa de sedimentação. Porém, as estruturas de HCS acrescionais descritas por Brenchley \& Newall (1982) são caracterizadas por uma base erosiva, que foi interpretada pelos autores como efeito de correntes de refluxo ligadas à tempestade. A falta de base erosiva na litofácies 1 indica ausência de correntes de alta energia antes da sedimentação e sugere uma rápi- da sedimentação por fluxos com alta carga sedimentar em suspensão e veloz decremento de energia das ondas (Kim 2003). As HCS acrescionais, também denominados form concordant HCS, refletem um crescimento vertical das lâminas com pouca ou nenhuma migração lateral do sedimento. A diminuição de espessura e de granulometria ascendente das lâminas dentro de uma mesma camada indica uma queda contínua da energia envolvida no transporte e deposição dos grãos (waning flow), que é característica do evento de tempestade. Da mesma forma, as marcas onduladas no topo das camadas da litofácies 1 denotam um decréscimo energético do fluxo. As marcas onduladas assimétricas são geradas pela tração de fundo em fluxos combinados onde a componente unidirecional pode ser gerada por correntes de pressão desenvolvidas pelas tempestades ou por atividade de maré. As marcas onduladas simétricas que moldam os topos das camadas são formadas por fluxos oscilatórios no final do evento de tempestade. A lâmi- 


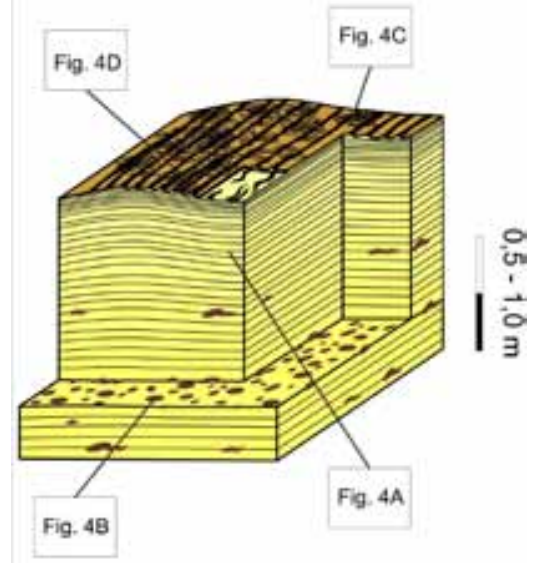

Figura 3 - Esquema gráfico de HCS (hummocky cross-stratification) de tipo acrescional (litofácies 1). Detalhes na figura 4.

na delgada pelítica, geralmente presente no topo da seqüência, é formada por decantação e denota condições de energia muito baixa ou de água parada. As gretas de dessecação indicam exposição subaérea destes sedimentos. Estas estruturas se distinguem de estruturas de dessecação subaquáticas (shrinkage cracks) porque as fraturas são interconectadas, separando pequenos polígonos, e preenchidas por arenitos. A emersão e consequente dessecação do pelito sugerem uma alternância de condições subaquáticas para subaéreas, provavelmente atreladas às oscilações da maré.

Litofácies 2: arenitos com estratificação cruzada tipo hummocky de erosão e preenchimento (scour and drapes hummocky cross-stratification) A litofácies 2 é formada por arenitos finos com boa seleção, que formam camadas lenticulares assimétricas, plano-convexas, com espessuras entre 0,1 e $1 \mathrm{~m}$ (Fig. 5). As lentes possuem uma extensão lateral $\leq 15 \mathrm{~m}$ e se distribuem na mesma superfície deposicional com espaçamento entre 1 e $7 \mathrm{~m}$ (Fig. 6A). Em planta estas lentes possuem forma elíptica. O contanto basal é plano e brusco, mas não erosivo. Camadas amalgamadas também ocorrem e formam pacotes que atingem espessuras superiores a 1,5 m. Internamente estas camadas possuem sets de estratificações onduladas ou cruzadas de baixo ângulo $<15^{\circ}$, em geral não superior

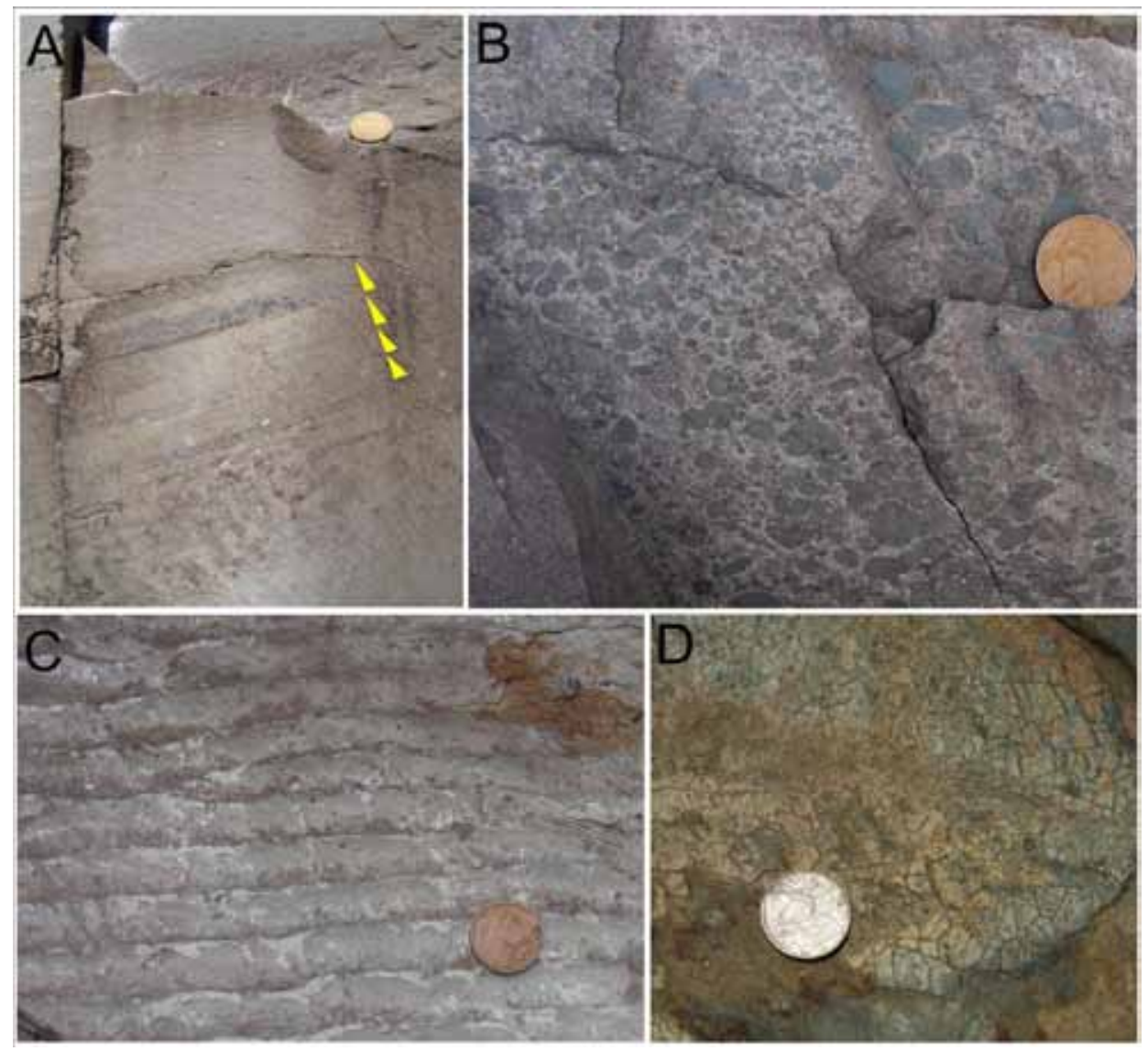

Figura 4 - HCS de tipo acrescional (litofácies 1). (A) Laminas plano-paralelas ou onduladas, gradadas e de espessura decrescente para cima. Moeda: diâmetro $24 \mathrm{~mm}$. (B) Clastos intraformacionais de pelito entre as lâminas plano-paralelas ou onduladas. Moeda: diâmetro $24 \mathrm{~mm}$. (C) Superficie das camadas com HCS que mostra marcas onduladas de ondas. As lâminas mais claras são de pelitos. Moeda: diâmetro $24 \mathrm{~mm}$. (D) Gretas de dessecação nos pelitos acima das camadas com HCS. Moeda: diâmetro $24 \mathrm{~mm}$. 


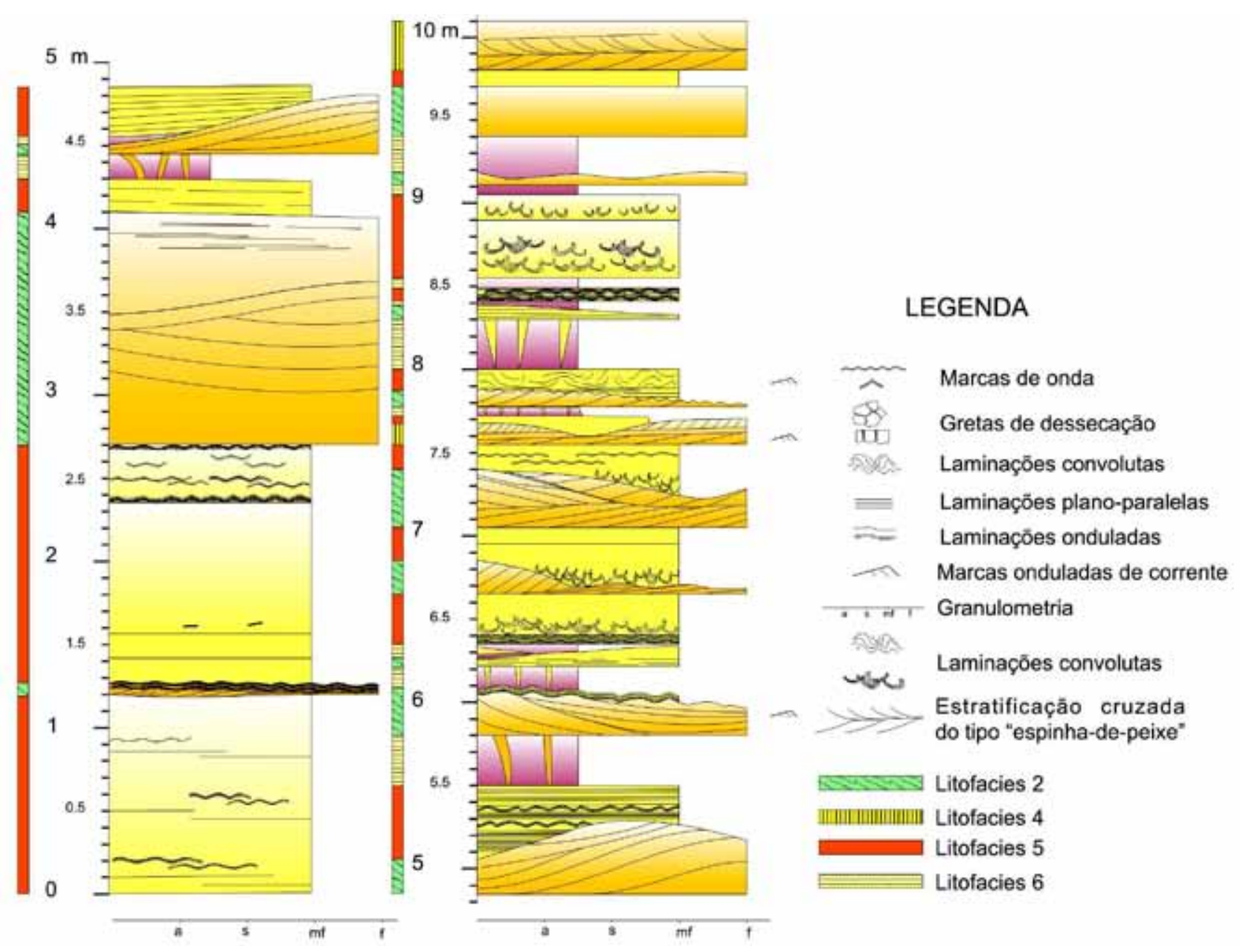

Figura 5 - Seção estratigráfica em localidade Serrinha, $N W$ de Lagarto (coordenadas geográficas UTM 641295/8797304). A seção representa a distribuição das litofácies 2, 4, 5 e 6 no elemento arquitetural $2 a$.
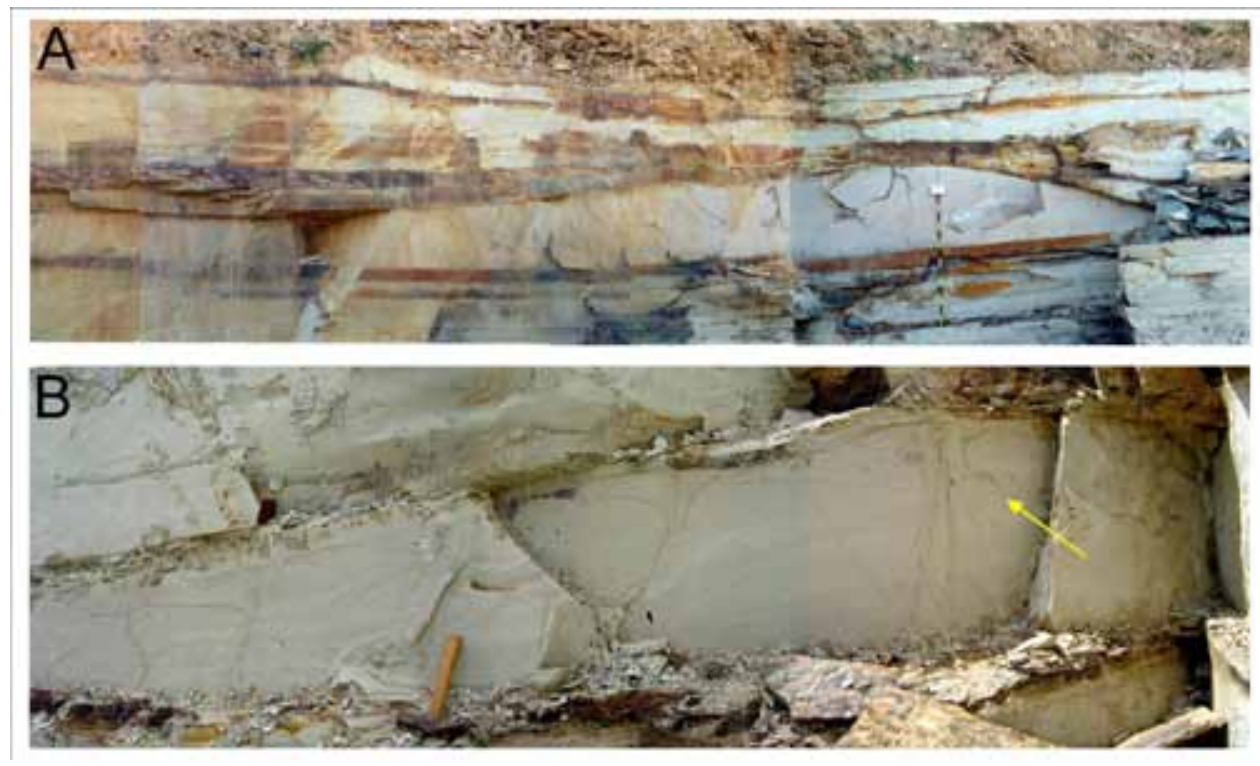

Figura 6 - HCS de tipo erosão e preenchimento (litofácies 2). (A) Esta litofácies é constituída por camadas lenticulares (plano-côncavas) de arenito fino com espaçamento de 1 a 7 m e espessura até 1,5 m. Bastão de Jacob: 1,5 m. (B) Internamente estas camadas são formadas por sets de estratificações cruzadas de baixo ângulo, onduladas e laminações plano-paralelas, separados por superficies erosivas (seta). Martelo: comprimento 0,25 m. 
que $5^{\circ}$ (Fig. 6B). Estas estratificações apresentam uma orientação preferencial e geralmente truncam-se entre si (Fig. 7A). Entretanto, pode haver estratificações com diferentes sentidos de mergulho que podem variar mais de $150^{\circ}$ na mesma camada. As estratificações cruzadas passam, lateral e verticalmente, para laminações planoparalelas (Fig. 7B). Marcas onduladas simétricas (wave ripples) são comuns acima das estratificações cruzadas. Estruturas de carga ocorrem, preferencialmente, nas bases das camadas. Frequentemente, o contato superior destes corpos é marcado pela presença de camadas de pelitos, maciças e comumente caracterizadas por gretas de dessecação (litofácies 6).

INTERPRETAÇÃO As estratificações internas da litofácies 2 permitem interpretar estas camadas como $H C S$ de erosão e preenchimento (scour and drapes hummocky cross-stratification). Segundo Dott \& Bourgeois (1982) a deposição destas estruturas ocorre pela queda de sedimentos a partir de suspensão associada à tração de fundo gerada por fluxos oscilatórios. As $H C S$ de erosão e preenchimento indicam a atuação concomitante de erosão e deposição (Craft \& Bridge 1987). O grande comprimento de onda destas estruturas indica condição de alta energia (Ito et al. 2001; Yang et al. 2006). A gradação vertical de $H C S$ para laminação plano-paralela e marcas onduladas indica uma queda da energia do fluxo da tempestade. As marcas onduladas simétricas presentes no topo de $H C S$ de erosão e preenchimento representam o retrabalhamento dos sedimentos por fluxos ondulatórios de baixa energia que ocorrem com a diminuição de energia da tempestade (Dott \& Bourgeois 1982).

Litofácies 3: arenitos com estratificação cruzada tipo hummocky migratória (anisotropic ou migrating hummocky cross-stratification) A litofácies 3 é constituída por camadas tabulares de arenitos finos - muito finos, com espessuras que raramente ultrapassam $0,3 \mathrm{~m}$ (Fig. 8A). As camadas possuem contato inferior brusco e erosivo e são organizadas em sets de laminações planas, onduladas e cruzadas assimétricas de baixo ângulo. As laminações cruzadas assimétricas formam aparentes marcas onduladas, porém, a transição entre plano de montantes e jusante das laminações é arredondada, faltando assim o ponto de ruptura (brink point) (Yokokawa et al. 1995) (Fig. 8B e C). O espaçamento das ondulações varia entre 0,08 e $0,35 \mathrm{~m}$. Cada set é separado de sets análogos por uma superfície erosiva, geralmente ondulada. As lâminas têm espessuras de poucos milímetros e podem apresentam pequenas variações laterais, sendo mais espessas nas porções côncavas e mais delgadas nas porções convexas. Verticalmente e lateralmente, as lâminas planas ou onduladas passam para laminações cruzadas com ângulos de inclinação variando entre 5 e $15^{\circ}$, que mergulham numa direção preferencial. Estruturas de convolução também ocorrem, podendo gerar dobras e forma tipo balls and pillows.

INTERPRETAÇÃO As características das estruturas sedimentares da litofácies 3 são típicas de HCS aniso-
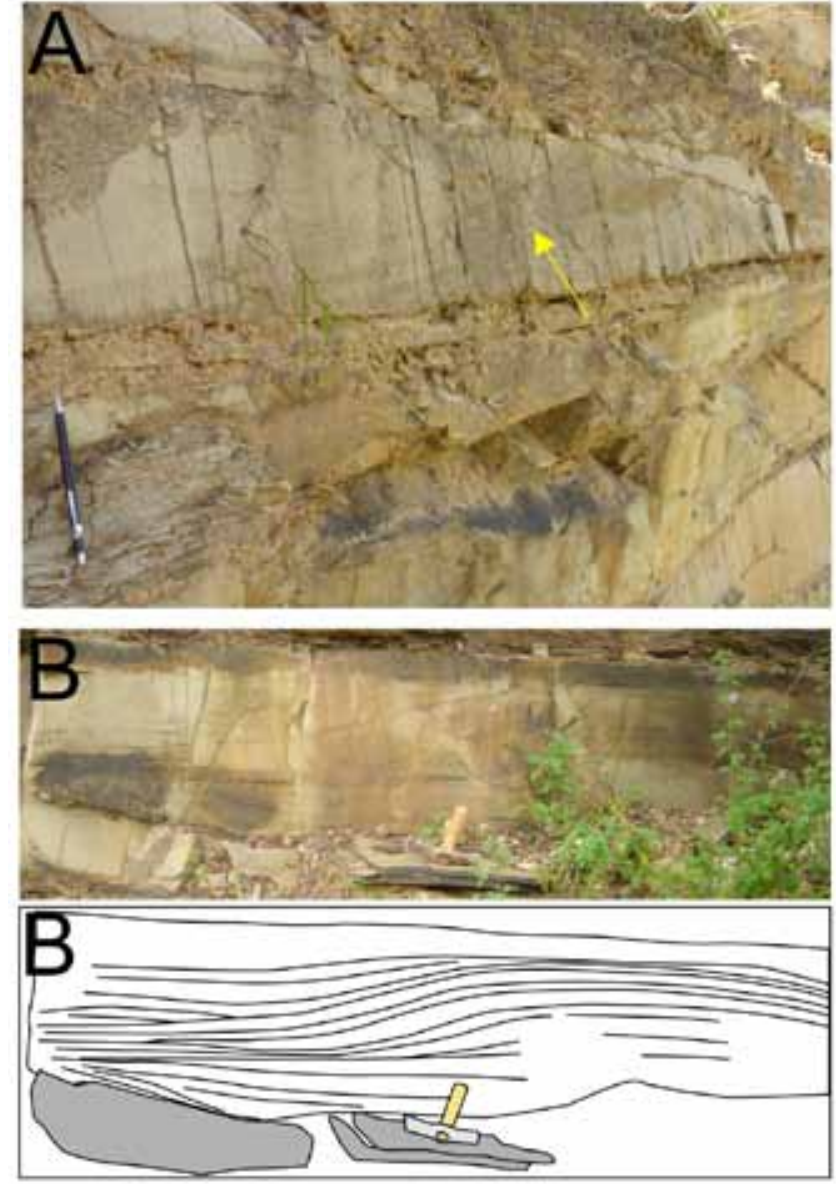

Figura 7 - HCS de tipo erosão e preenchimento (litofácies 2). (A) Sets de estratificações cruzadas de baixo ângulo separadas por superficies erosivas (seta). Lapiseira: $143 \mathrm{~mm}$. (B) Estratificações cruzadas que passam lateralmente para estratificações onduladas ou planas. Martelo: comprimento 0,25 m.

trópicas (ou HCS migratórias, Cheel \& Leckie 1993). Aparentemente, estas estruturas são semelhantes com marcas onduladas assimétricas cavalgantes, geradas por fluxo unidirecional, entretanto, o baixo ângulo de inclinação e a convexidade dos foresets e a transição lateral destas estruturas para lâminas onduladas, permitem atribuí-las a fluxos combinados (oscilatórios e unidirecionais). Os foresets destas estruturas não são gerados por avalanche, como ocorre nas marcas onduladas geradas por fluxos unidirecionais, mas sim pela tração de grãos decorrente de fluxos hidráulicos combinados (Myrow et al. 2002). Dumas et al. (2005), a partir de ensaios em laboratório, reproduziram estruturas semelhantes, que denominaram de Assimetric Small Ripples, cujas principais características são: espaçamento entre 0,11 e $0,21 \mathrm{~m}$, altura da crista de 12 a $29 \mathrm{~mm}$, cristas sem ponto de ruptura, contendo planos jusantes e montantes convexos. Estas estruturas são geradas pela associação de fluxos unidirecionais e fluxos oscilatórios. As estruturas convolutas são estruturas de deformações geradas em sedimentos não compactados por liquefação associada à alta taxa de sedimentação (Allen 1982). 

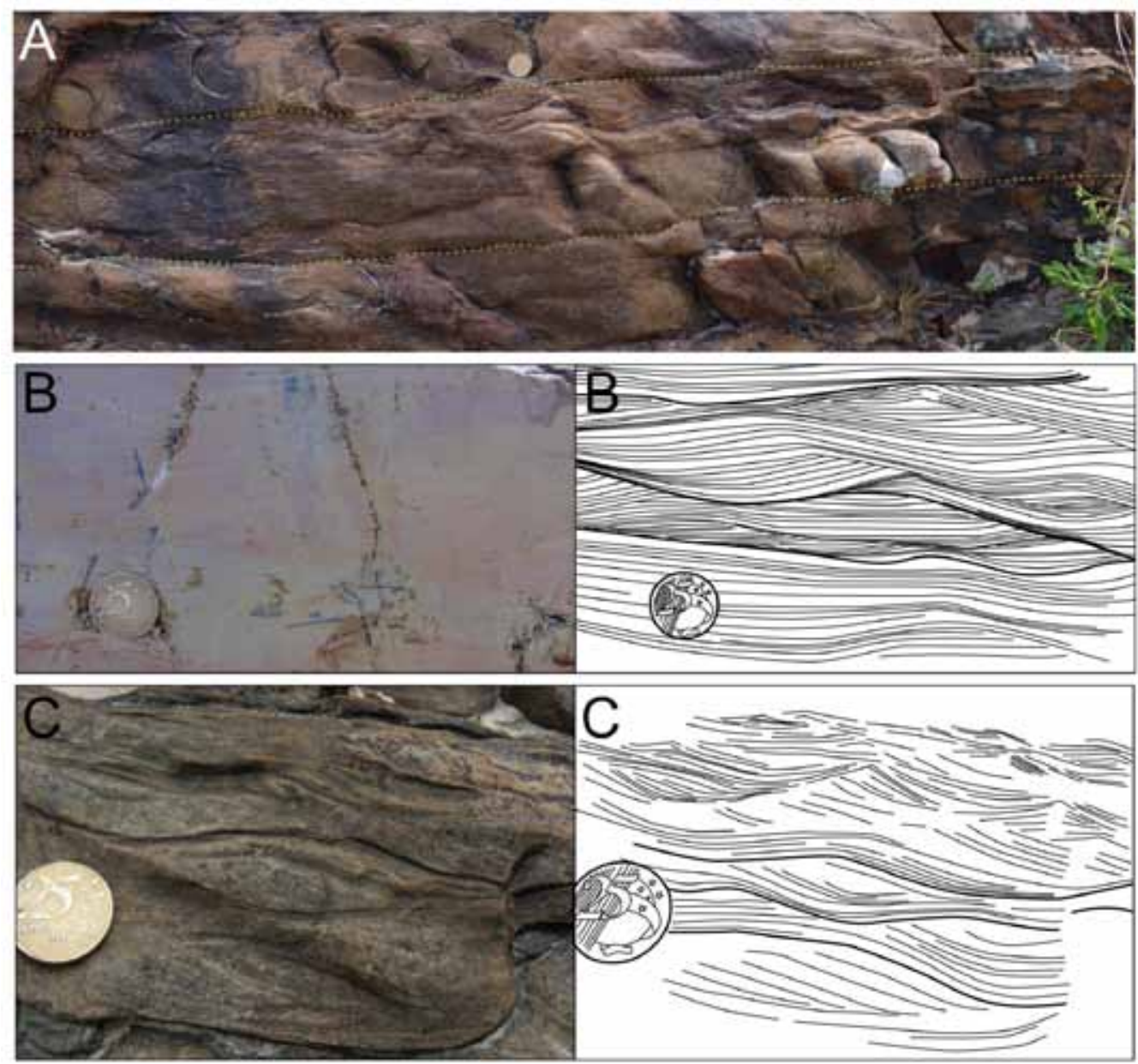

Figura 8 - HCS de tipo migratória (litofácies 3). (A) Arenitos finos com HCS de espessura não maior que 0,3 m e espaçamento até 0,35 m. Às vezes estas camadas são cobertas por marcas de onda. As linhas tracejadas indicam base e topo da camada. Moeda: diâmetro $24 \mathrm{~mm}$. (B e C) Estruturas internas com estratificações onduladas e cruzadas de baixo angulo unidirecionais, que formam marcas onduladas com topo arredondado e sem ponto ruptura entra lado de montante e jusante. Moeda: diâmetro $24 \mathrm{~mm}$.

\begin{abstract}
Litofácies 4: Camadas de arenito com estratificações cruzadas A litofácies 4 é constituída por camadas de arenito fino - muito fino, de seleção moderada ou boa, espessura até $0,3 \mathrm{~m}$, e que, na escala dos afloramentos (50 m lateralmente), possuem geometrias tabulares. Os contatos inferiores e superiores das camadas são erosivos. Estas camadas exibem uma estratificação cruzada tangencial com sets, $0,1-0,3 \mathrm{~m}$ espessos, que às vezes formam estratificação cruzada do tipo "espinha-de-peixe" (Fig. 9A) ou são organizados em estruturas a forma de sigmóide, onde os foresets são separados por laminas de pelito (Fig. 9B). Esta litofácies é relativamente rara e encontrada interestratificada com as litofácies 3 e 5 .
\end{abstract}

INTERPRETAÇÃO Estratificações cruzadas com estruturas de tipo sigmóides e do tipo "espinha-de-peixe" indicam influências de correntes bidirecionais devidas a marés. A primeira estrutura é interpretada como sigmoidal tidal bundles.

\section{Litofácies 5: Arenitos muito finos com laminação}

plano-paralela e marcas onduladas simétricas A litofácies 5 é composta por arenitos muito finos, de boa seleção granulométrica, que formam camadas de espessura entre 0,04 e 0,2 m (Fig. 10A). Em geral, as camadas possuem geometria tabular, no entanto, podem ser lenticulares quando formadas sobre superfícies irregulares. A característica principal desta litofácies é a presença de laminações cruzadas de forma simétrica formadas por marcas onduladas (wave ripples). Na superfície deposicional as marcas onduladas possuem cristas retilíneas e bifurcadas, podendo ser arredondadas ou, mais subordinadamente, em forma de cúspide (Fig. 10B). O espaçamento destas formas de fundo pode chegar a $40 \mathrm{~mm}$ e a amplitude a $15 \mathrm{~mm}$. Os sets de marcas onduladas simétricas podem ocorrer por toda a camada ou se sobrepor a lâminas plano-paralelas. A laminação plano-paralela é constituída por lâminas ou camadas delgadas, 1-20 mm espessas, marcadas por gradação normal de areia fina para areia muito fina e silte e/ou por bruscas variações de granulação. Intraclastos de pelito, até $5 \mathrm{~cm}$ longos, estão em geral alocados em superfícies preferenciais, situadas nas partes inferiores da 

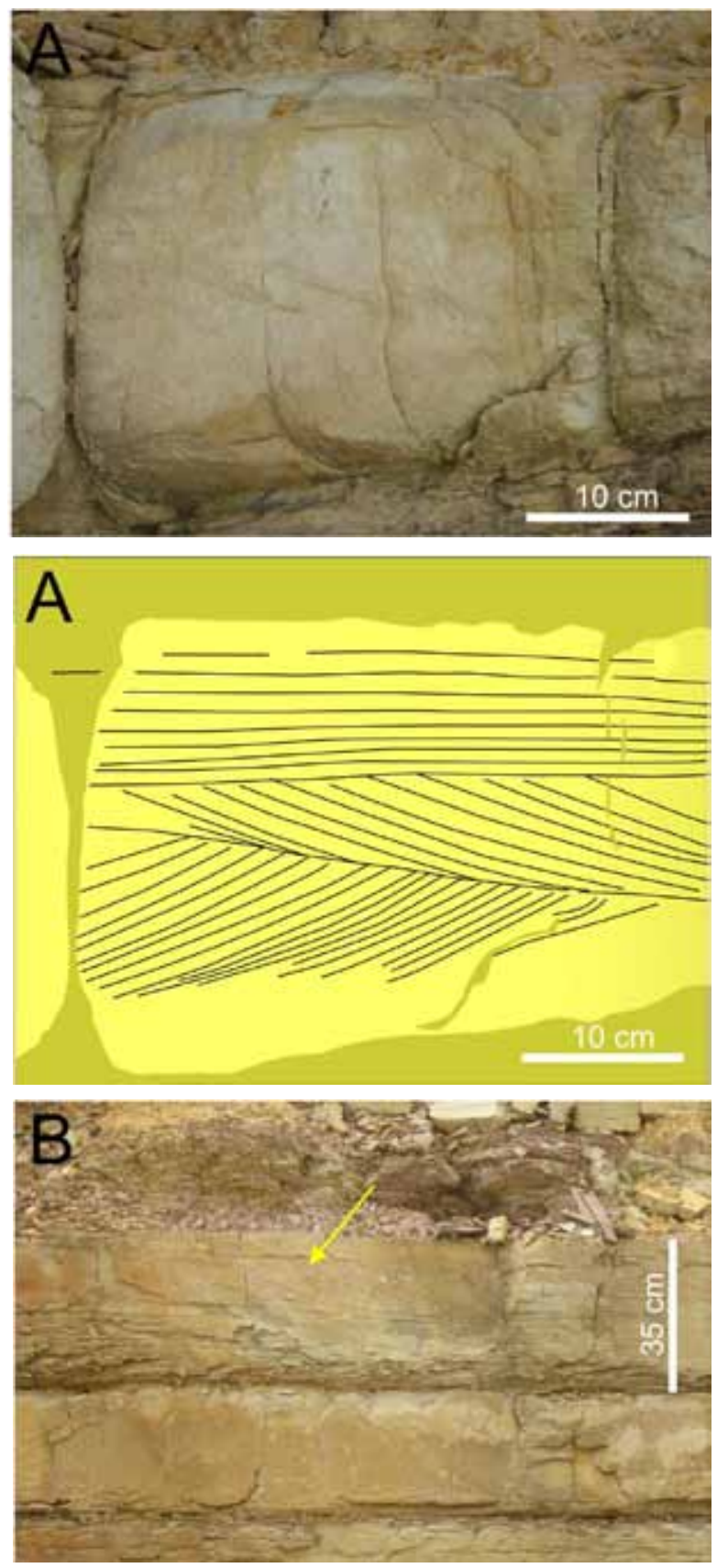

Figura 9 - Arenito com estratificações cruzadas (litofácies 4). (A) Estratificações cruzadas que formam uma estrutura a espinha de peixe. (B) Estratificações cruzadas com forma sigmoidal e intercalações de pelitos nos foresets (seta). Estas estruturas são interpretadas como sigmoidal tidal bundles.

porção com laminação plano-paralela. Acamadamento flaser também ocorre (Fig. 10C).

INTERPRETAÇÃO As estruturas presentes nesta litofácies são formadas em condições de baixa energia por fluxos oscilatórios. A sobreposição de sets com marcas onduladas indica condições de alta taxa de sedimentação. $\mathrm{O}$ acamadamento flaser indica ritmicidade das condições de energia de transporte e sedimentação e pode ser relacionada à atividade da maré. Laminas plano-paralelas
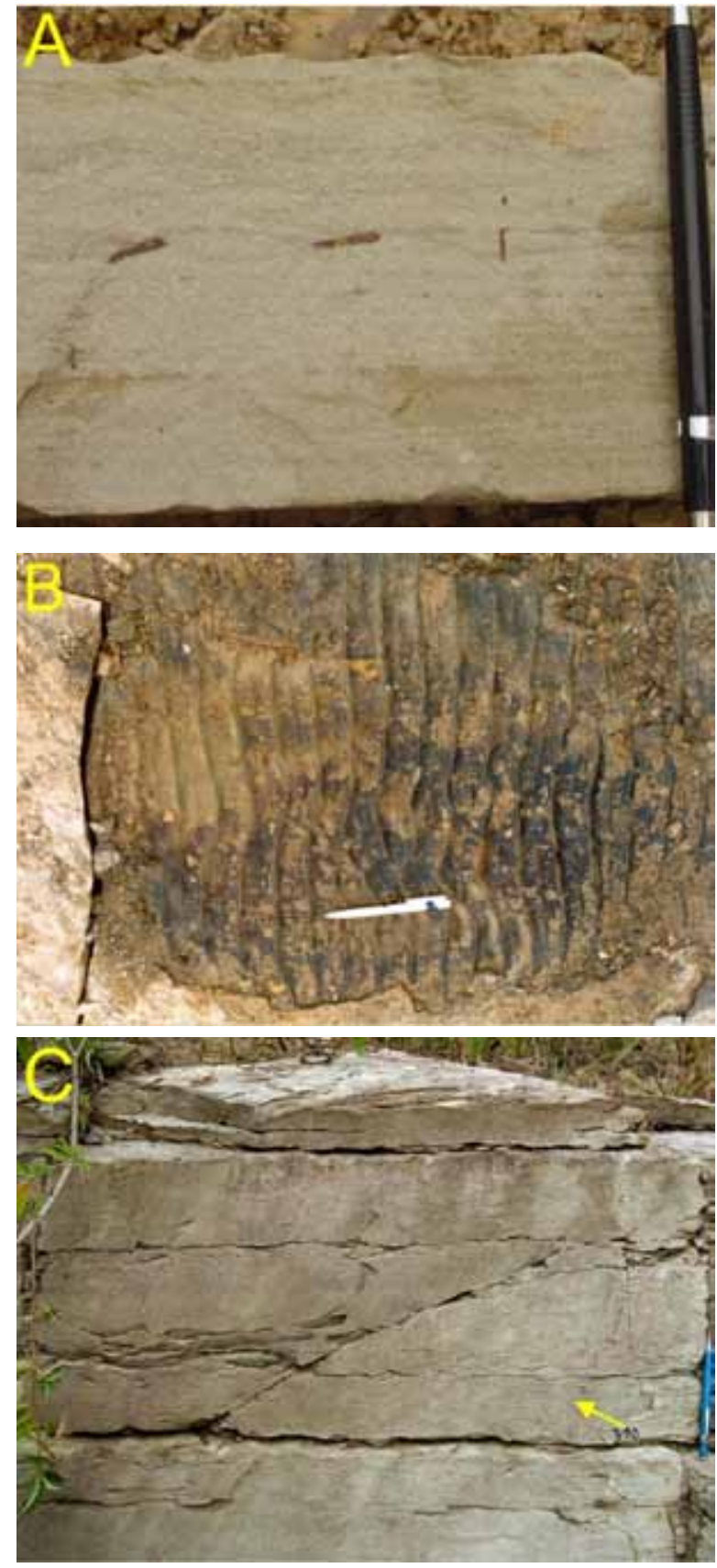

Figura 10 - Arenitos com laminação plano-paralela e marcas onduladas simétricas (litofácies 5). (A) Camadas de arenito muito fino constituídas por laminações plano-paralelas ou cruzadas de muito baixo ângulo na base e marcas de ondas na porção superior. Lapiseira: $143 \mathrm{~mm}$. (B) Topo de camadas com marcas de onda. Caneta: $143 \mathrm{~mm}$. (C) Acamadamento tipo flaser (seta). Lapiseira: $143 \mathrm{~mm}$.

podem ser formadas em condições de leito plano por ondas ou fluxos combinados de maior energia (Myrow \& Southard 1991). A transição vertical de laminação planoparalela a marcas onduladas indica condições de decréscimo de energia do evento deposicional.

Litofácies 6: Camadas delgadas de pelitos Esta litofácies é constituída por camadas de pelito com es- 
pessura que varia de alguns milímetros a $0,3 \mathrm{~m}$. As camadas possuem uma continuidade lateral limitada, de menos de $1 \mathrm{~m}$ a poucas dezenas de metros, com numerosas variações de espessura, principalmente em função da morfologia das camadas subjacentes (Fig. 11A). Esta litofácies não mostra estruturas internas a não ser gretas em forma de cunha preenchidas de arenitos, com até $0,2 \mathrm{~m}$ de profundidade (Fig. 11B), que na superfície deposicional correspondem a gretas de dessecação. Em planta, estas gretas formam polígonos, cujo maior eixo varia de 5 a $300 \mathrm{~mm}$ (Fig. 11C). $\mathrm{Na}$ superfície das camadas de pelito ocorrem marcas de pingo de chuva (Fig. 9D). Estas camadas de pelito cobrem as litofácies 1, 2, 3 e 4 .

INTERPRETAÇÃO Esta litofácies é formada por decantação de lama em ambientes de baixa energia. A intercalação com depósitos areníticos sugere a deposição durante fase de estagnação da água, provavelmente conexas com a fase de parada do fluxo de maré (slacking water). Gretas de dessecação e marcas de pingo de chuva indicam condições de emersão e evaporação.

Litofácies 7: Pelito intercalado a camadas delgadas ou lâminas de arenito A litofácies 7 é constituída por pelito interestratificado a lâminas, lentes e camadas delgadas de arenito. A porção arenítica em geral não supera $20 \%$ de espessura da litofácies (Fig. 12A e B). O pelito é constituído por camadas com espessuras entre
1 e 70 mm. As lâminas de arenito são plano-paralelas, compostas por arenito muito fino siltoso, com espessuras de $<1 \mathrm{~mm}$ até $2 \mathrm{~mm}$ e muito continuas lateralmente, mais de $70 \mathrm{~m}$ (limite horizontal de afloramento). As lentes são de arenito muito fino, possuem forma planoconvexa, de simétrica a sutilmente assimétrica, e espessura entre 2 e $30 \mathrm{~mm}$. Estas lentes mostram laminações cruzadas com mergulho preferencial ou bidirecional, com foresets sempre de forma tangencial e com inclinação máxima de $15^{\circ}$, geralmente menor que $10^{\circ}$ (Fig. $12 \mathrm{C}$ e D). Às vezes camadas distintas mostram foresets com direções opostas. Estratificações de tipo lenticular (sensu, Reineck \& Singh 1980) são frequentes. As camadas tabulares de arenitos possuem espessura entre poucos centímetros e $0,5 \mathrm{~m}$, e são formadas por arenito muito fino em parte siltoso. Estas camadas mostram marcas onduladas cavalgantes assimétricas com lado de montante preservado (do tipo B de Jopling \& Walker 1968) e lâminas de pelitos (mud drapes) que cobrem ciclicamente as marcas onduladas (Fig. 12E). Gretas de dessecação preenchidas por arenitos são observadas na superfície de estratificação. Comumente, algumas camadas, de espessuras até $0,2 \mathrm{~m}$, ocorrem deformações pós-deposicionais plásticas, que consistem em dobras de fechadas a cerradas, inclinadas a invertidas, cujos planos axiais mergulham sem nenhuma direção preferencial (Fig. 12B). Esta litofácies forma sucessões com espessura de mais de $50 \mathrm{~m}$.
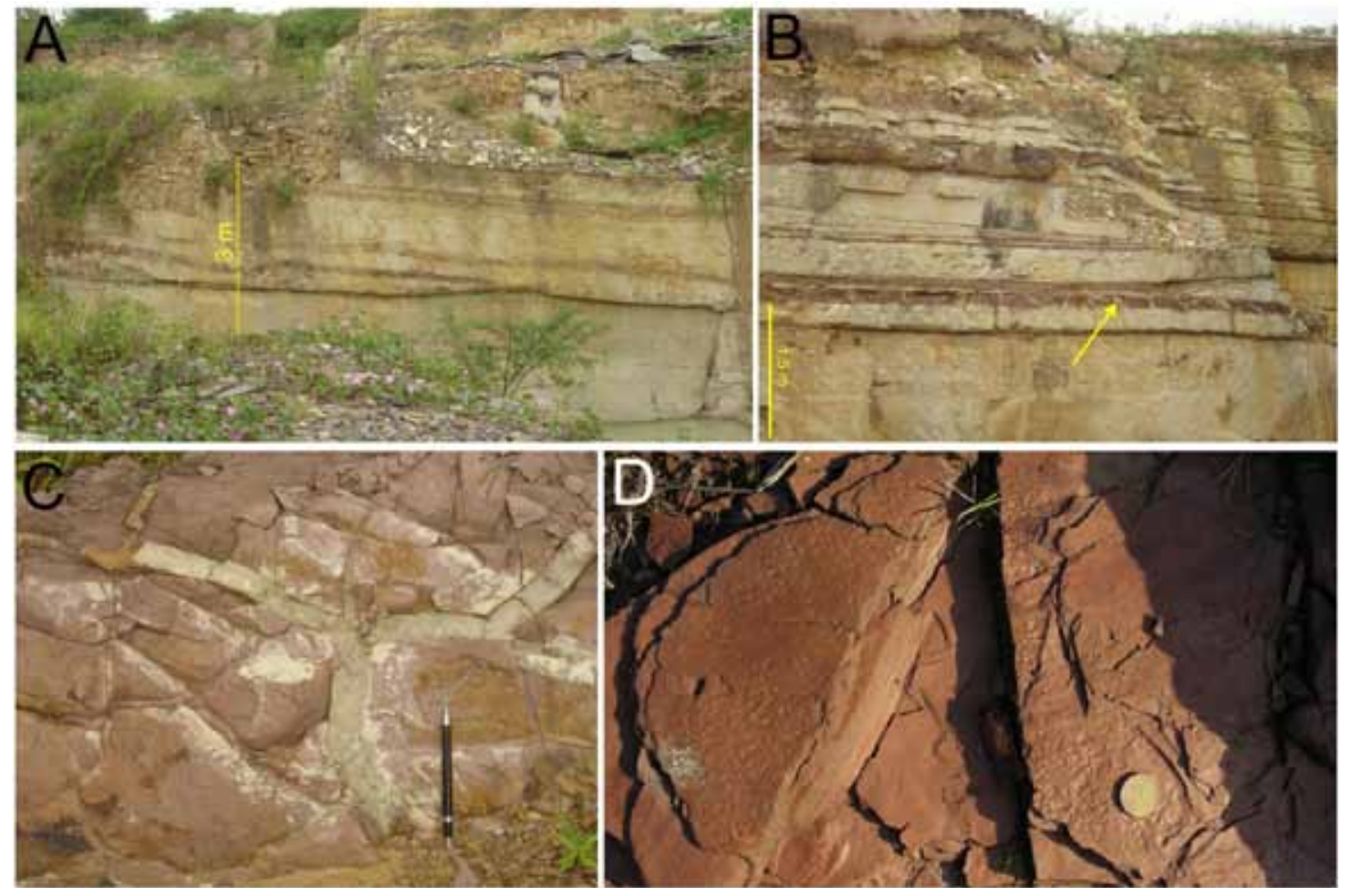

Figura 11 - Camadas delgadas de pelito (litofácies 6). (A) Camadas de pelito com afinamento lateral para direita. (B) Fissura de dessecação preenchida por arenitos (seta), que indicam fases de emersão. (C) Gretas de dessecação na superficie de camada. Lapiseira: $143 \mathrm{~mm}$. (D) Marcas de pingo de chuva na superfície de camada de pelitos. Moeda: diâmetro $24 \mathrm{~mm}$. 

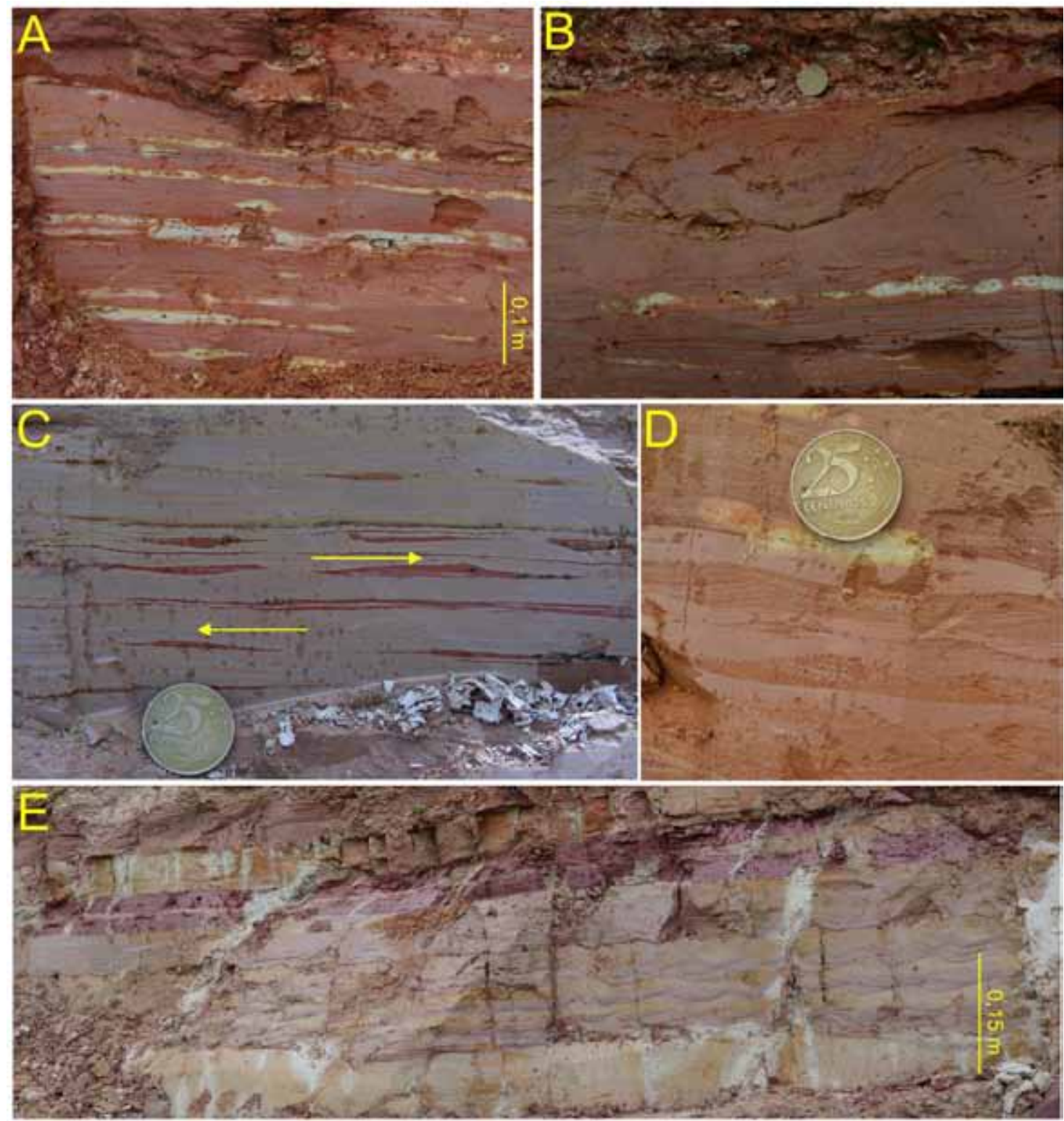

Figura 12 - Pelito intercalado a camadas delgadas ou lâminas de arenito (litofácies 7). (A) Pelito laminado com interstratificações de lâminas ou lentes achatadas de arenitos muito finos. (B) Pelitos com intercalações de arenito muito fino. Na porção superior se observam laminações convolutas atribuídas a deformação pós-deposicional por ondas sísmicas. Moeda: diâmetro 24 $\mathrm{mm}$. (C) Pelitos com marcas de correntes que mostram direção opostas de movimento (setas). (D) Marcas onduladas simétricas atribuídas a atividade de ondas ou fluxos combinados. Moeda: diâmetro $24 \mathrm{~mm}$. (E) Marcas onduladas assimétricas cavalgantes atribuiveis a ritmitos de maré.

INTERPRETAÇÃO Esta litofácies foi depositada em ambiente subaquático de baixa energia que apresentava variações periódicas das condições energéticas e que era sujeito a emersão. Estas alternâncias sistemáticas de energia sugerem ciclicidade relacionada às variações das correntes de maré, que em áreas de intermaré superior produzem depósitos rítmicos de granulometria variável (Tessier 1993; Tessier 1998). Nesta área a velocidade dos fluxos é apenas suficiente para o transporte e deposição de areia muito fina por tração e formação de marcas onduladas e lâminas plano-paralelas. Gretas de dessecação se formavam durante os períodos de mí- nima excursão da maré, provavelmente durante a quadratura (Tessier et al. 1995). Camadas de arenito muito fino com marcas onduladas cavalgantes e lâminas de pelito (mud drapes), similares com aquelas descritas, foram observadas por Lanier e Tessier (1998) na porção mais interna do estuário de Mont-Saint-Michel (França) (confronte a Fig. 12E com a Fig. 4F de Lanier \& Tessier 1998). Estes autores interpretaram esta fácies como característica do domínio misto (fluvial/mareal) do estuário na área superior da zona de intermaré. As variações de espessura dos arenitos e da frequência das lâminas de pelito, individualizam ciclicidade dos 
processos deposicionais ligados ás fases quinzenais de sizígia e quadratura da maré. As deformações plásticas pós-deposicionais, a causa da ausência de direção preferencial das dobras, podem ser hipoteticamente interpretadas como causadas por sucessivos abalos sísmicos, que desencadearam a fluidização dos sedimentos.

ELEMENTOS ARQUITETURAIS As litofácies presentes na Formação Lagarto são agrupadas em três elementos arquiteturais. Estes elementos arquiteturais foram distinguidos segundo os seguintes critérios: espessura relativa das camadas areníticas e lamíticas, organização e distribuição relativa das litofácies. Os três elementos arquiteturais representam três porções de uma área costeira de intermaré, como será explicado mais abaixo. A descrição deles será feita do mais distal até o mais proximal com relação à costa.

Elemento arquitetural 1: depósitos de área de intermaré inferior $\mathrm{O}$ elemento arquitetural 1 é composto majoritariamente ( $85 \%$ da espessura) por camadas areníticas de granulação fina com estratificação cruzada de tipo hummocky acrescional (litofácies 1). Estas camadas são interestratificadas com arenitos muito finos com marcas onduladas simétricas (litofácies $5-15 \%$ da espessura do elemento) e raras lâminas de pelito (litofácies 6) (Fig. 13A). Este elemento forma corpos sedimentares que em afloramento foram observados com a espessura máxima de $60 \mathrm{~m}$ e a extensão lateral máxima de $300 \mathrm{~m}$ (Fig. 13B).

As duas litofácies que constituem este elemento não são distribuídas em sequências verticais ordenadas. As camadas da litofácies 1 se sobrepõem uma com a outra sem base erosiva, simplesmente se adaptando à morfologia ondulada das camadas inferiores (Fig. 13C). De fato, tanto as pequenas marcas de onda, quanto as lâminas de pelitos com greta de dessecação e delicadas estruturas biogênicas, atribuíveis a esteiras microbianas (Renata G. Netto, comunicação pessoal, 2009), se encontram perfeitamente conservadas na parte superior das camadas. Camadas que pertencem à litofácies 5 , com espessura entre 0,4 e $1,5 \mathrm{~m}$, se interestratificam às camadas da litofácies 1 em modo aparentemente casual formando corpos tabulares (Fig. 13B e D). As lâminas de pelito (litofácies 6) cobrem a parte superior das litofácies 1 ou se interestratificam mais comumente nos arenitos muito finos da litofácies 5, constituindo lâminas ou lentes delgadas côncavas entre as marcas onduladas, nesse último caso formando um acamadamento flaser. A preservação de pelito é praticamente irrelevante neste elemento arquitetural, porém o ambiente deposicional gerou condições favoráveis para a deposição de lama, como é testemunhado pela comum presença de clastos de pelito até $7 \mathrm{~cm}$ longos, nas laminações das $H C S$ acrescionais (litofácies 1).

Cada camada da litofácies 1 representa um evento deposicional gerado por um fluxo oscilatório de tempestade. A deposição destas camadas aconteceu sem ser antecipada por fenômenos erosivos da superfície deposicional subjacente, provavelmente por causa da alta carga sedimentar dos fluxos durante a tempestade. O processo de deposição destas camadas ocorreu por progressiva diminuição da energia oscilatória (waning flow), como sugerido pela gradação e pela presença de estruturas deposicionais que para cima decrescem de dimensão e energia deposicional. Os depósitos da litofácies 5 indicam condições deposicionais de energia inferior com relação à litofácies 1 . Fluxos oscilatórios e unidirecionais participaram à deposição destas camadas, como indicado pelas marcas onduladas tridimensionais e com crista arredondada. Condições de água parada (slacking water) determinaram a deposição de lama entre as marcas onduladas. A presença de gretas de dessecação e esteiras microbianas indica deposição em área de água de baixa profundidade com frequentes emersões.

Estes elementos permitem afirmar que o elemento arquitetural 1 se depositou numa área costeira sujeita a frequentes emersões e dominada por processos deposicionais ligados a tempestades. Por estas razões e em relação aos outros elementos arquiteturais, como será discutido mais para frente, o ambiente sedimentar do elemento 1 é colocado numa área de intermaré inferior.

Elemento arquitetural 2: depósitos de área de intermaré intermediária $\mathrm{O}$ elemento 2 é constituído pela maior variedade de litofácies: arenitos com estratificação cruzada tipo $H C S$ de erosão e preenchimento (litofácies 2) e migratória (litofácies 3), arenitos com estratificações cruzadas (litofácies 4), arenitos muito finos com marcas onduladas simétricas (litofácies 5) e camadas delgadas de pelitos (litofácies 6). Este elemento pode ser subdividido em dois sub-elementos ( $2 \mathrm{a}$ e $2 \mathrm{~b}$ ), que se diferenciam principalmente pela distribuição das litofácies.

O sub-elemento 2 a mostra a seguinte distribuição de espessura das litofácies: litofácies $2(39 \%)$, litofácies 5 (34\%), litofácies $6(15 \%)$ e litofácies 4 (12\%) (Fig. 14A e B). A litofácies 2 (HCS de erosão e preenchimento), que domina este sub-elemento, forma camadas lenticulares, plano-convexas, 0,1-1 m espessas, que internamente mostram HCS de tipo erosão e preenchimento (Fig. 14C). Estas lentes comumente são amalgamadas, separadas ou não por uma camada delgada de pelito e mostram um espaçamento entre 1 e $7 \mathrm{~m}$. Esta litofácies é frequentemente coberta por arenito muito fino com laminações planoparalelas e marcas de onda cavalgantes (litofácies 5; Fig. 14D) e pelitos com gretas de dessecação (litofácies 6; Fig. 14E). Mais raramente se interestratificam arenitos finos com estratificações cruzadas, com formas de tipo sigmoidal e a espinha de peixe (litofácies 4).

O sub-elemento 2 b (Fig. 15A e B) é dominado por camadas tabulares de arenito fino e muito fino com estruturas de $H C S$ migratórias (litofácies 3; Fig. 15C), às vezes cobertas por marcas de ondas (litofácies 5 ; Fig. 6), alternadas com pelitos (litofácies 6), que mostram estruturas de exposição subaérea (gretas de dessecação e marcas de pingo de chuva) (Fig. 15D e E). A distribuição em espessura dos pelitos neste sub-elemento é de cerca de 20\%; as camadas com marcas de onda não superam o $15 \%$. As camadas com $H C S$ migratórias 

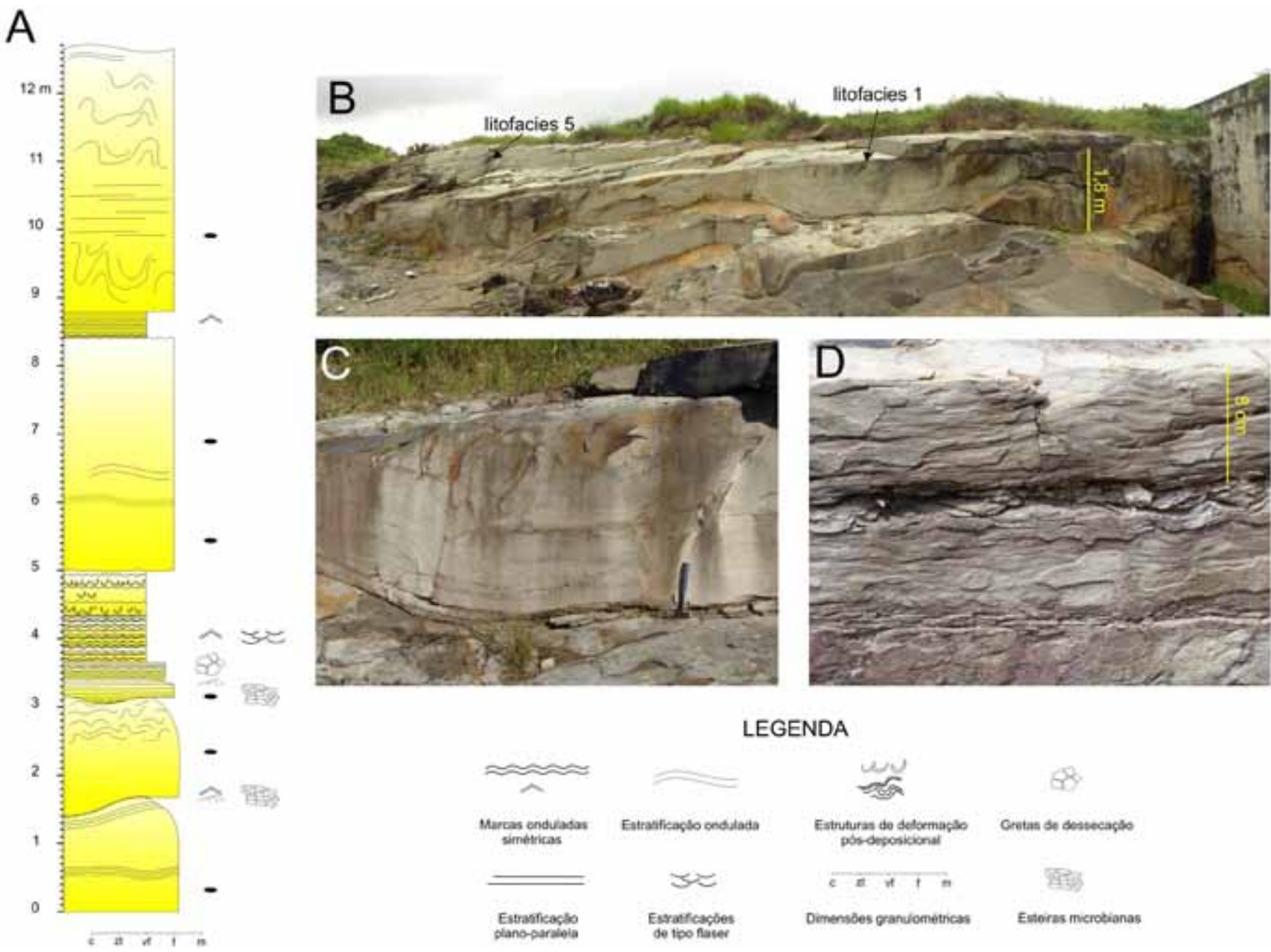

LEGENDA

Figura 13 - Elemento arquitetural 1 - Depósitos de área de intermaré inferior. (A) Seção estratigráfica de um afloramento do elemento arquitetural 1. (B) O elemento 1 é composto por depósitos de HCS acrescionais (litofácies 1) e secundariamente por camadas de arenitos com marcas de onda (litofácies 5). (C) HCS acrescionais com base ondulada, não-erosiva (litofácies 1). O topo é mais claro por ser coberto por pelito. Martelo: 0,25 m. (D) Camadas de arenitos muito finos com marcas de onda (litofácies 5).

possuem uma espessura que varia de 0,1 a $0,3 \mathrm{~m}$ e um espaçamento lateral de $0,15-0,3 \mathrm{~m}$.

Os dois sub-elementos mostram que a ação das ondas era dominante nos processos deposicionais, mas vários aspectos permitem uma marcada diferenciação com relação ao elemento 1. (1) A abundância de camadas de pelitos (litofácies 6) sugere que fases de baixa energia e estagnação das águas (slacking waters) eram mais comum que no sistema deposicional representado pelo elemento 1. (2) Os depósitos de tempestade são caracterizados por camadas de granulação, espessura e espaçamento inferior que os encontrados no elemento 1, além de serem formados por outros tipos de HCS. (3) Depósitos de ondas de baixa energia (litofácies 5) são mais frequentes nos sub-elementos 2. (4) A ação de fluxos uniou bidirecionais é mais marcada nos sub-elementos 2 .

$\mathrm{O}$ sub-elemento $2 \mathrm{~b}$ se diversifica do $2 \mathrm{a}$ por não mostrar camadas da litofácies 4 e por ser dominado por camadas de HCS migratórias (65\% da espessura).

A interpretação de fácies identifica a área deposicional dos sub-elementos 2 como uma área costeira, sujeita à atividade de ondas de tempestade e de baixa energia, mas também caracterizada por uma alta frequência das fases de estagnação das águas e emersão, e também pela presença de fluxos uni- e bidirecionais ligados à ação das marés. As menores dimensões e granulometria das $H C S$ migratórias nos sub-elemento $2 \mathrm{~b}$ sugerem que este se formou numa área mais proximal e mais protegida à ação das ondas que o sub-elemento 2a (Le Hir et al. 2000).

\section{Elemento arquitetural 3: depósitos de área de inter-} maré superior O elemento arquitetural 3 é composto principalmente por pelitos, interestratificados a lâminas ou camadas delgadas lenticulares de arenitos (litofácies 7 - 95\% da espessura deste elemento), mais raramente aparecem camadas de arenitos tabulares, espessas até $1,5 \mathrm{~m}$, com estratificação cruzada tipo $H C S$ anisotrópica (litofácies 3 - 5\% da espessura) (Fig. 16A e B). Em afloramento foram medidos até $35 \mathrm{~m}$ deste elemento, mas a sua distribuição areal mostra que forma sucessões com espessura superior a $200 \mathrm{~m}$ e extensão lateral maior que $1 \mathrm{~km}$. Este elemento é provavelmente o mais extenso e espesso dos três, embora as suas exposições sejam raras e de dimensões menores quando compara- 

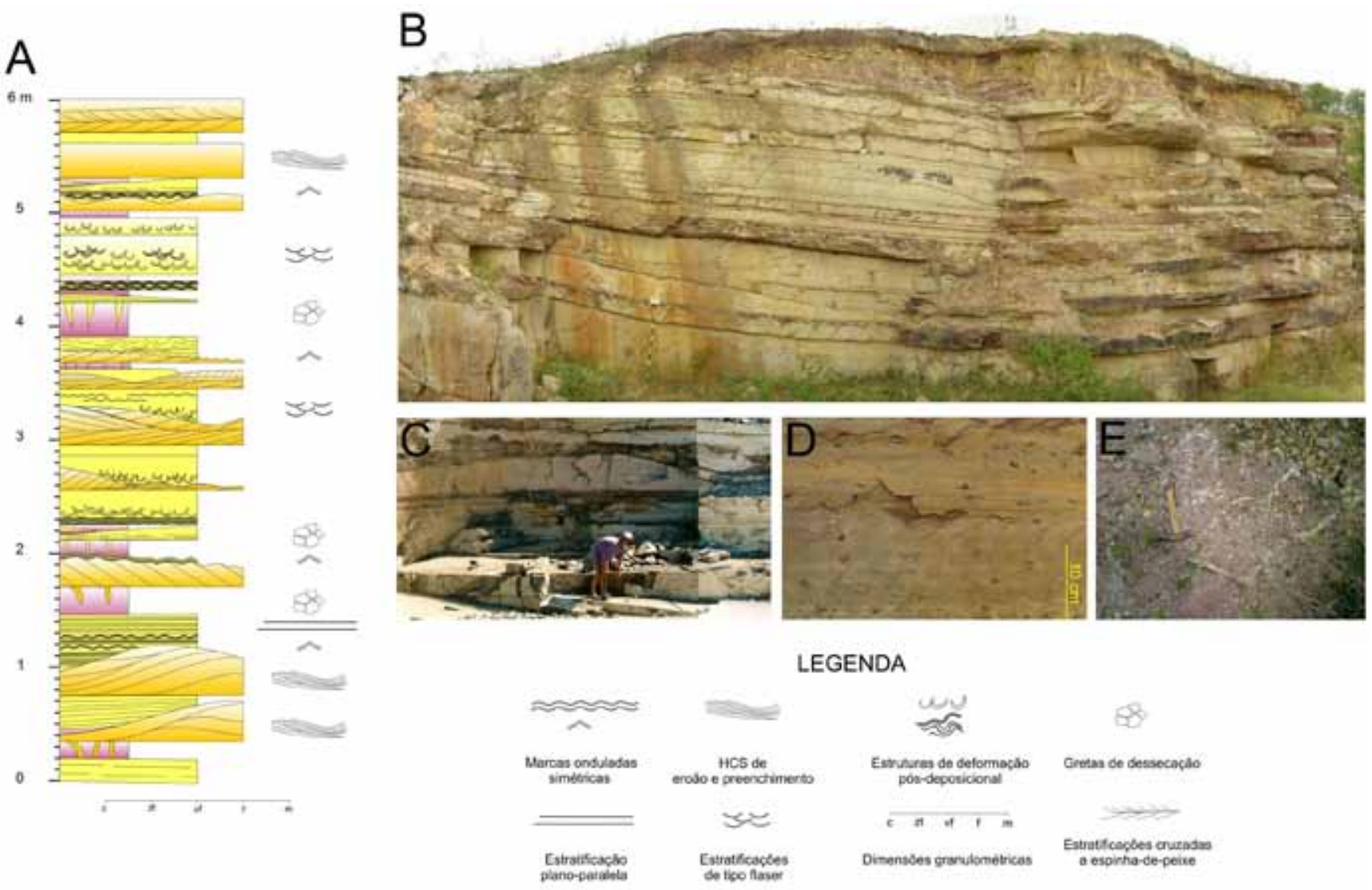

LEGENDA

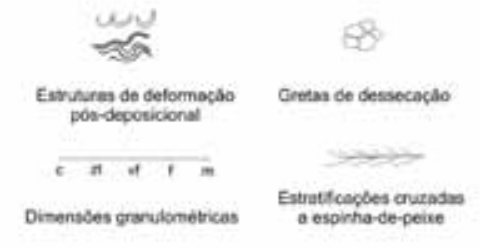

Figura 14 - Elemento arquitetural 2 a - Depósitos de área de intermaré intermediária. (A) Seção estratigráfica de um afloramento do elemento arquitetural 2 a. (B) Afloramento do elemento $2 a$. As camadas lenticulares são arenitos com HCS de erosão e preenchimento (litofácies 2), as camadas mais escuras são de pelito (litofácies 6). Bastão de Jacob: 1,5 m. (C) Camadas lenticulares de HCS de erosão e preenchimento (litofácies 2). Pessoa para escala. (D) Marcas de ondas simétricas cavalgantes (litofácies 5). (E) Gretas de dessecação na superficie de pelitos (litofácies 6). Martelo: 0,25 m.

do aos outros dois elementos.

A abundância de depósitos lamíticos que variam entre 50 e $80 \%$ da espessura indica condições energéticas de deposição muito baixas em áreas protegidas de fluxos oscilatórios ou unidirecionais. A comum presença de estruturas de dessecação (Fig. 16C) neste elemento arquitetural confirma também que as condições deposicionais se desenvolviam em áreas com frequentes emersões. Os arenitos que se alternam com os pelitos variam de simples lâminas com espessura menor que $1 \mathrm{~mm}$, contínuas lateralmente, a lentes achatadas com laminações cruzadas espessa até $2 \mathrm{~cm}$ (Fig. 16D). Estas estruturas são similares às litofácies descritas por De Raaf et al. (1977) correspondentes às litotipos M1, variedade a e b, e M2, variedade a. Tais alternâncias de arenitos e pelitos podem ser definidos como ritmitos de maré (tidal rhythmites), uma vez que ocorrem lentes de arenitos com foresets com mergulho bidirecional, gretas de dessecação e estratificações de tipo lenticular (Fan et al. 2004). A atividade deposicional das marés é reconhecida também nas camadas com marcas onduladas cavalgantes (Fig. 16E), onde os foresets de arenito são ciclicamente alternados com lâminas de pelito. Segundo a interpretação de Lanier \& Tessier (1998) este tipo de organização representaria a alternância de fases de sizígia e quadratura em áreas de planície de maré.

A influência de correntes de maré é o processo sedimentar dominante neste elemento arquitetural, embora ocorram depósitos ligados a fluxos de tipo oscilatório de baixa energia. Esporadicamente tempestades excepcionais romperam o isolamento desta área deposicional gerando camadas de arenitos até $1,5 \mathrm{~m}$, que são caracterizados por estruturas interpretadas como $H C S$ migratórias.

Por todos estes aspectos o elemento arquitetural 3 é inserido num contexto de ambiente de intermaré superior e, como será explicado em baixo, menos profundo e mais proximal do que aqueles ambientes representados pelos outros elementos.

\section{DISCUSSÃO}

Modelo deposicional A descrição de sistemas deposicionais costeiros não-deltaicos, atuais e antigos, na literatura é comumente baseada em modelos simplificados, nos quais há um único processo dominante (ondas ou correntes de maré) (Dalrymple et al. 1992; Reading 1996; Davis \& Fitzgerald 2004). Porém, os sistemas costeiros são áreas em que atuam vários mecanismos de distribuição e deposição de sedimentos, tanto ligados à atividade de ondas, como à atividade de marés, que de- 

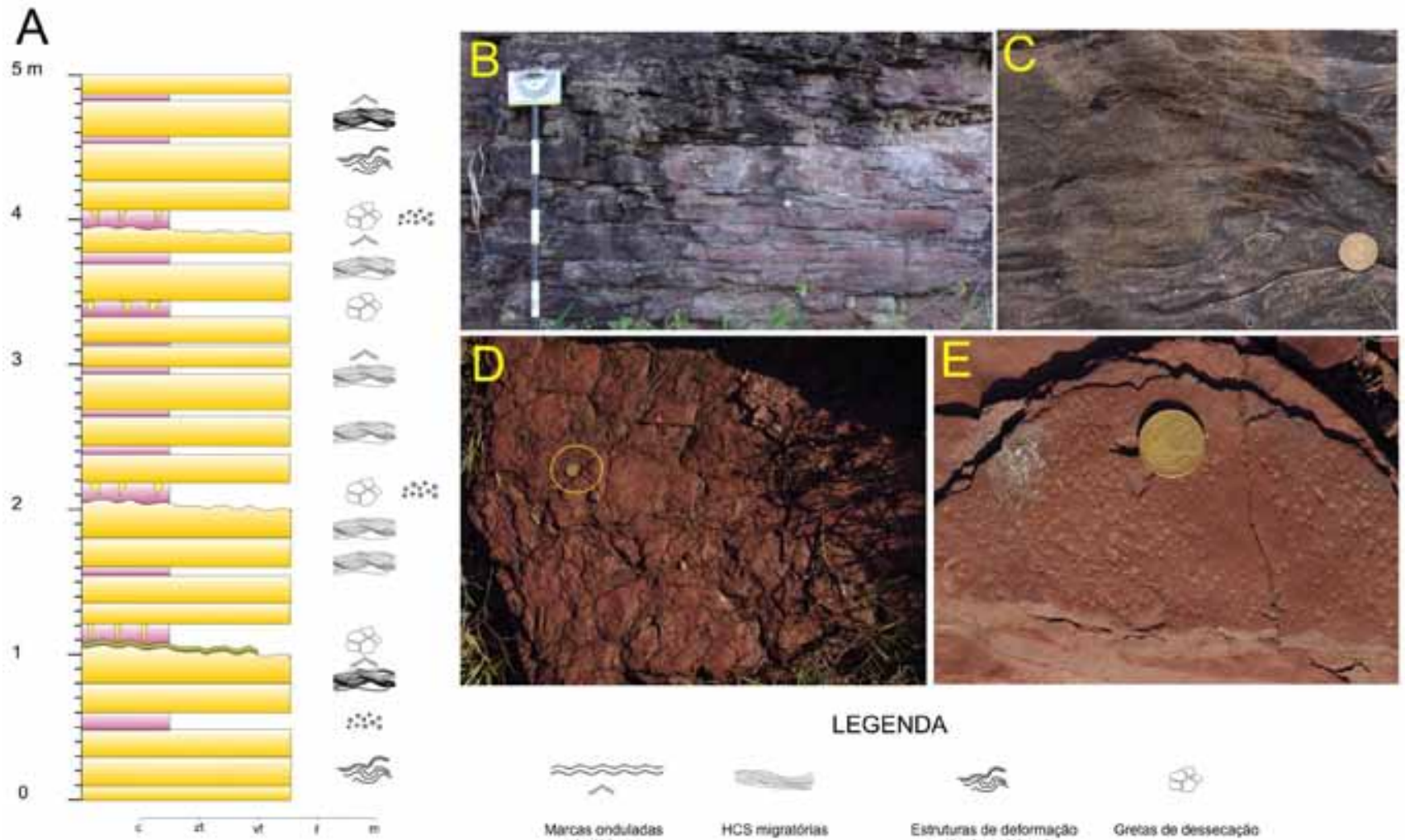

LEGENDA
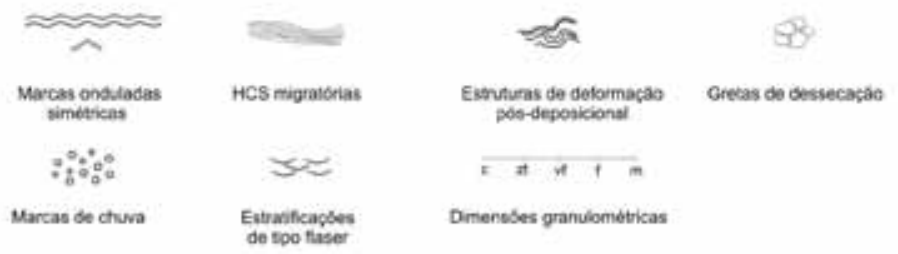

Figura 15 - Elemento arquitetural $2 b$ - Depósitos de área de intermaré intermediário. (A) Seção estratigráfica de um afloramento do elemento arquitetural $2 b$. (B) O elemento $2 b$ é constituído por camadas delgadas de arenito fino alternadas com pelito. As barras do bastão de Jacob são de 0,1 $\mathrm{m}$. (C) Arenitos com estruturas de HCS migratórias (litofácies 2). Sentido de migração para esquerda (litofácies 6). Moeda: $24 \mathrm{~mm}$. (D) Gretas de dessecação acima de pelitos (litofácies 6). Moeda (cercada): $24 \mathrm{~mm}$. (E) Marcas de pingo de chuva (litofácies 6). Moeda: $24 \mathrm{~mm}$.

terminam as propriedades das fácies e a geometria dos corpos sedimentares (Dalrymple et al. 2006). Boyd et al. (1992) propuseram uma classificação dos ambientes deposicionais costeiros, que abrange a maioria dos ambientes sedimentares clásticos mais comuns, incluindo deltas, praias, planície de maré e lagunas. Esta classificação, que inclui tanto aspectos morfológicos como a evolução dos sistemas deposicionais, está baseada nos processos dominantes que controlam o transporte e deposição sedimentar (Fig. 17A). A classificação é descrita mediante um diagrama triangular, cujos vértices mostram os principais fatores que controlam o sistema costeiro: rios, ondas e marés. Yang et al. (2005) fizeram uma modificação desta classificação diversificando entre os sistemas deposicionais de costas dominadas por onda e costas dominadas por marés, praia de marés (tidal beaches) e planície de maré aberta (open-coast tidal flat) (Fig. 17B).

A Formação Lagarto foi depositada em um sistema deposicional costeiro híbrido, cujas características sedimentares permitem interpreta-lo como uma planície de maré aberta influenciada por ondas. De fato, as camadas da Formação Lagarto mostram feições que testemunham a interação dos dois processos deposicionais. Acamadamento de tipo lenticular e flaser, estruturas sigmóides e estratificação cruzada espinha-de-peixe, lâminas de lamítos, ritmitos de maré (respectivamente litofácies 4, 5, 6 e 7) podem ser produzidas por correntes de marés. Por enquanto $H C S$ acrescionais, $H C S$ migratórios, $H C S$ de erosão e preenchimento, marcas onduladas simétricas ou debilmente simétricas (respectivamente litofácies 1, 2, 3 e 5) são feições mais típicas de fluxos oscilatórios ou combinados.

Embora se encontrem indícios de produtos deposicionais por ondas e marés em todos os três elementos arquiteturais, estes são representados por litofácies diferentes, que são distribuídas em modo variado nos elementos. A maioria da atividade oscilatória de onda é registrada na Formação Lagarto por depósitos de tempestade. Espessas camadas de arenitos formadas por $H C S$ de tipo acrescional e camadas de menor espessura e espaçamento de $H C S$ migratórias e de erosão e preenchimento constituem respectivamente a maioria ou boa parte da espessura dos elementos arquiteturais 1 e 2. Depósitos de movimentos oscilatórios de baixa 
A
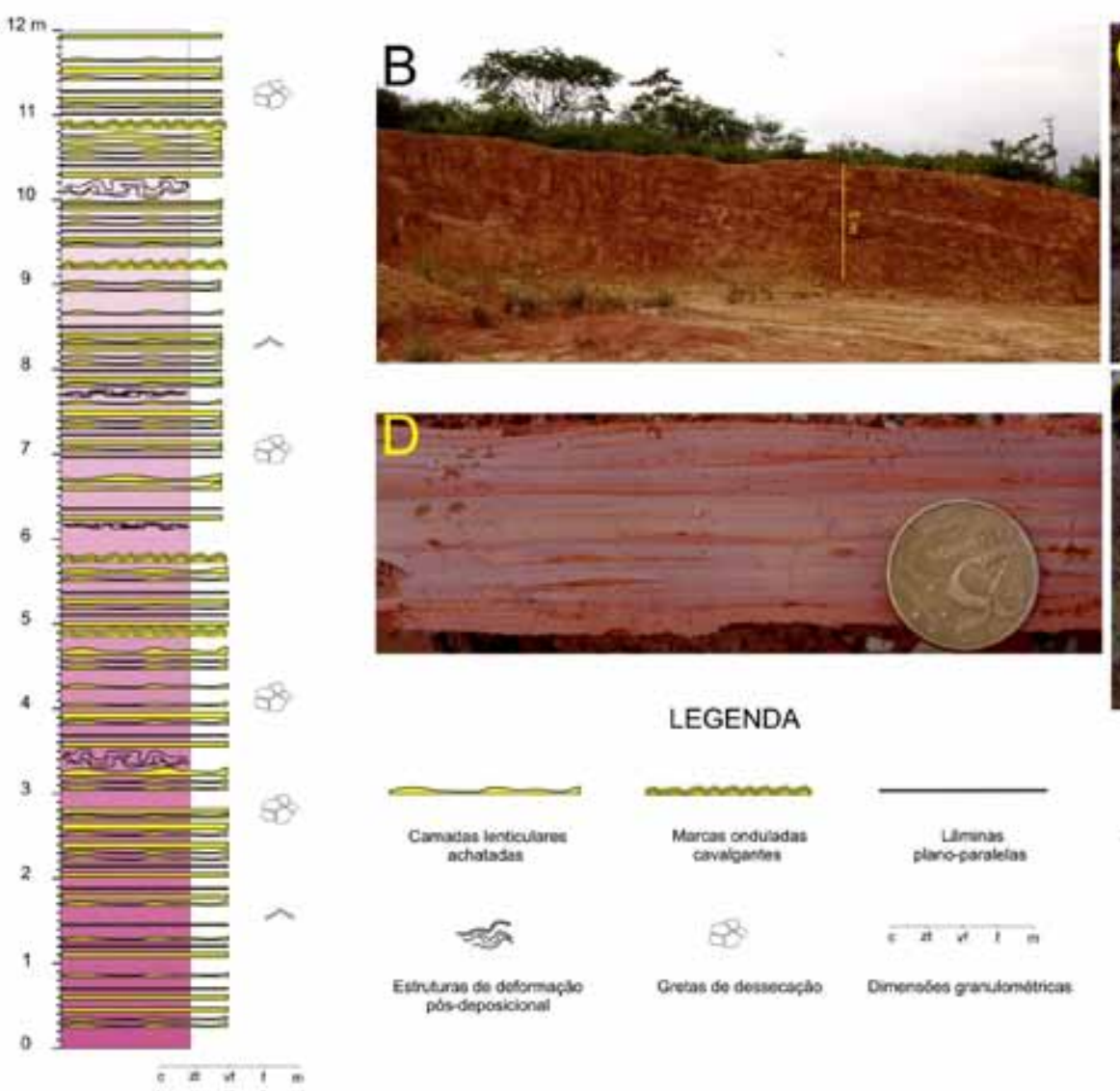
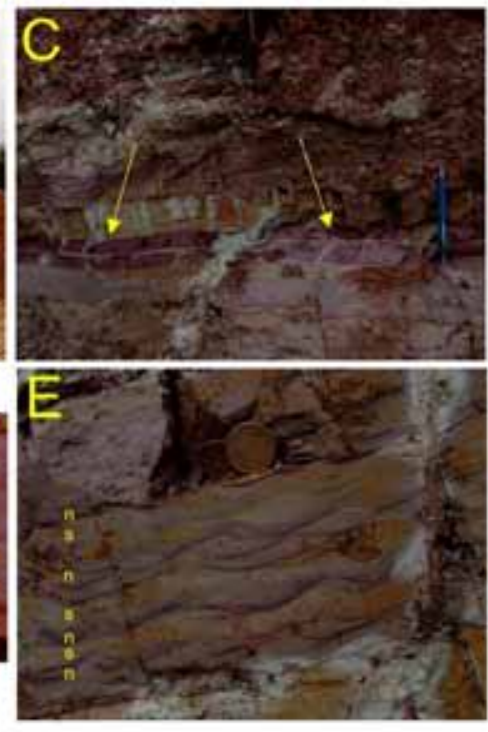

LEGENDA

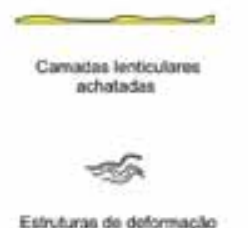

possonoposicional

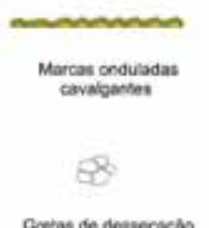

Creas de desuccastas

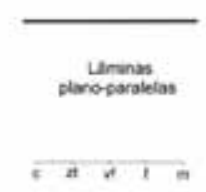

Dinensbes gravionotricas.

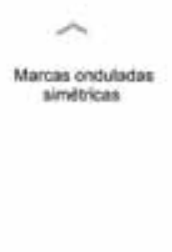

Figura 16 - Elemento arquitetural 3 - Depósitos de área de intermaré superior. (A) Seção estratigráfica de um afloramento do elemento arquitetural 3. (B) Afloramento do elemento 3. As camadas mergulham para direita. (C) Gretas de dessecação preenchidas de arenito muito fino (litofácies 7). Lapiseira: $143 \mathrm{~mm}$. (D) Lentes achatadas de arenito muito fino (litofácies 7). Moeda: $24 \mathrm{~mm}$. (E) Marcas onduladas assimétricas cavalgantes alternadas com lâminas de pelito (mais escuro). Esta estrutura é interpretada como ritmito de maré e representa ciclo de sizígia e quadratura. n: quadratura. s: sizígia. Moeda: $24 \mathrm{~mm}$.

velocidade orbital, que são associáveis a condições de tempo bom, são responsáveis pelas marcas de onda, simétricas ou pouco assimétricas, encontradas em todos os elementos arquiteturais. Todavia, na Formação Lagarto faltam os indícios de uma atividade de movimentos das ondas mais constante e de condições energéticas intermediárias, capazes de construir corpos arenosos de praia submersa superior (upper shoreface) e praia emersa (foreshore).

Depósitos associados à atividade das marés são constantemente observados em todos os elementos arquiteturais. Estes são indicados pela presença de pelito que cobre marcas onduladas (acamadamento flaser), arenitos com estratificações cruzadas e intercalações de lâminas de pelitos (estruturas de tipo sigmoidal), camadas com marcas onduladas cavalgantes e camadas espessas de poucos milímetros até alguns decímetros de pelito, alternadas com os arenitos. Os efeitos das correntes de marés são provavelmente presentes também na componente unidirecional que se combina com o movimento oscilatório e que gera marcas onduladas assimétricas ou $H C S$ de tipo anisotrópico. A influência da maré é dominante no elemento arquitetural 3, que foi interpretado como parte superior de uma planície de intermaré. Todavia, na Formação Lagarto faltam depósitos que são mais típicos de costas dominadas por marés, como, por exemplo, canais e barras de submaré ou canais meandrantes de planície de intermaré.

Para construir um modelo de distribuição horizontal dos elementos arquiteturais (trato de fácies, cf. Mutti 1992) e reconstruir as características deposicionais do sistema que gerou a Formação Lagarto foram buscados critérios que pudessem distinguir a proximalidade e distalidade dos elementos arquiteturais em relação à linha de costa. $\mathrm{O}$ modelo produzido pressupõe que na sucessão estudada (aproximadamente $1300 \mathrm{~m}$ de espessura) não existam variações substanciais do sistema deposicional. De fato, os três elementos arquiteturais descritos se distribuem em modo bastante uniforme na área estudada, sugerindo certa continuidade do sistema deposicional na Formação Lagarto.

Todos os afloramentos examinados da Formação Lagarto, por uma extensão maior que $400 \mathrm{~km}^{2}$, mostram depósitos com estruturas sedimentares que in- 

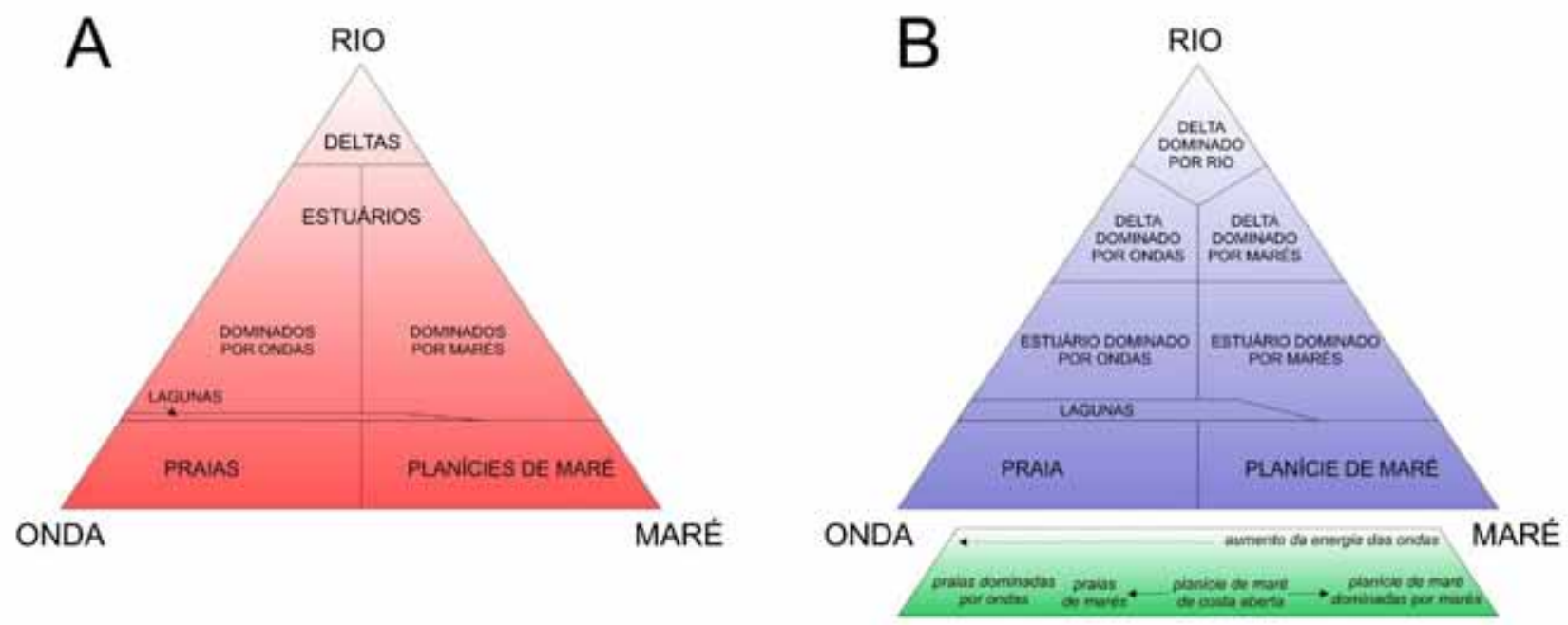

Figura 17 - Esquemas de classificação de sistemas deposicionais costeiros. (A) Modelo modificado de Boyd et al. (1992). (B) Modelo modificado de Yang et al. (2005).

dicam atividade de maré e frequentes emersões, sugerindo que a costa fosse caracterizada por uma inclinação muito leve. Nestas condições morfológicas os efeitos das marés e das ondas progressivamente diminuíam de energia na direção da terra emersa. Em áreas costeiras com importante ação das marés tal fato se identifica com um progressivo aumento da componente lamosa nos sedimentos, desta forma a relação da espessura de areia/lama pode ser usada como fator que indica distalidade e proximalidade com relação à linha de costa. Os valores da relação de espessura arenito/pelito pelos elementos arquiteturais $1,2 \mathrm{a}, 2 \mathrm{~b}$ e 3 são, respectivamente: $99,5,3,5$ e 0,25 (Fig. 18). Estes valores indicam um progressivo aumento da componente lamosa nos sedimentos do elemento 1 ao $3 \mathrm{e}$, portanto, sugerem um progressivo aumento da proximalidade do elemento 1 ao 3 . Esta distribuição horizontal dos elementos arquiteturais é confirmada pela distribuição da energia dos processos deposicionais, conforme pode ser deduzido da interpretação das litofácies. $\mathrm{O}$ elemento arquitetural 1 , o mais distal, mostra as maiores condições energéticas de deposição: granulação maior (arenitos médios e finos) e $H C S$ acrescionais, com comprimento de onda até $14 \mathrm{~m}$, que constituem as estruturas sedimentares dominantes e testemunham condições de alta energia durante tempestades marinhas. As condições energéticas que depositaram areia diminuem no elemento $2 \mathrm{a}$, onde as ondas geraram $H C S$ de erosão e preenchimento com comprimento de onda de poucos decímetros até $7 \mathrm{~m}$ e as marés geraram dunas $\leq 20 \mathrm{~cm}$. O elemento $2 \mathrm{~b}$ mostra $H C S$ migratórias de arenitos fino-muito finos com espaçamento lateral de $0,08-0,35 \mathrm{~m}$ e espessura máxima de $0,3 \mathrm{~m}$. O elemento 3 testemunha condições de baixa energia de deposição das areias, representadas por pequenas marcas onduladas assimétricas ou simétricas e cavalgantes, produzidas por atividade de marés, ondas ou fluxos combinados.

Da porção distal à proximal a ação das ondas diminui tanto em força quanto em frequência. No elemento arquitetural 1 a maioria das camadas (75\%) são constituídas por $H C S$ de tipo acrescionais. No elemento $2 \mathrm{a}$ e $2 \mathrm{~b}$ as camadas de arenito produzidas por $H C S$ constituem respectivamente $39-65 \%$ da espessura. No elemento 3 a atividade das ondas constitui $10 \%$ da espessura do mesmo, sendo o restante constituído por camadas formadas por ação das marés. De forma contrária, a influência da deposição pela atividade de maré, ou da combinação de marés e ondas de baixa velocidade orbital, aumenta na direção distal - proximal, passando de $25 \%$ da espessura das camadas no elemento 1 até $90 \%$ no elemento 3 .

Baseando-se nestes critérios foi construído um modelo de sedimentação costeira como mostrado em figura 18, que é caracterizado pela influência mista de ondas e marés, com um predomínio deposicional das ondas de tempestade na parte mais distal e de marés na porção mais proximal.

Todos os elementos arquiteturais são intercalados a camadas ou lâminas de pelitos com gretas de dessecação ou marcas de pingo de chuva, claras evidências de temporárias exposições subaéreas. Este fato implica que tais depósitos tenham sido formados em áreas de intermaré pouco profundas (alguns metros de lâmina de água).

Comparação com outros modelos Yang et al. (2005), Dalrymple et al. (2006) e Yang et al. (2008) geraram um modelo de sedimentação em planícies de marés dominadas por ondas em costas abertas baseado nos exemplos atuais da planície de maré de Baeksu (Coréia sul ocidental) e da baia de Parksville (nordeste da Ilha de Vancouver, Canadá). Os autores observaram que planícies de marés dominadas por ondas ocupam uma posição intermediária entre ambientes deposicionais costeiros dominados por marés e por ondas. Neste modelo os processos deposicionais são controlados pelo clima. Durante o verão a ausência de ventos fortes e a baixa atividade dos movimentos das ondas favorecem a ação das marés nos processos deposicionais e a planície de maré é caracterizada por deposição de lama 


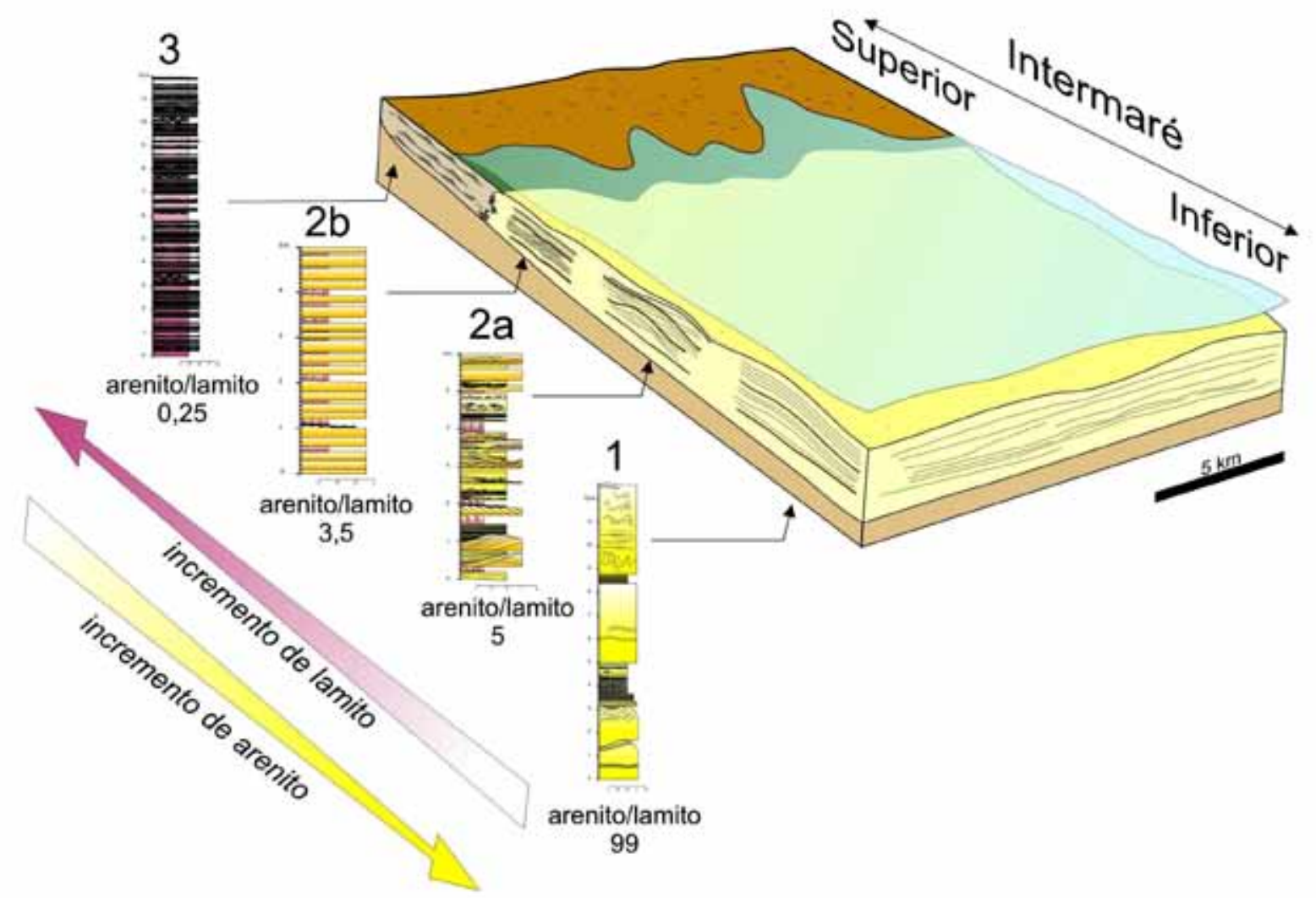

Figura 18 - Modelo deposicional da Formação Lagarto. Os números acima das colunas estratigráficas correspondem aos elementos arquiteturais.

com raras lâminas de areia. Durante o inverno, quando os fortes ventos geram tempestades frequentes, a sedimentação é predominantemente arenosa, os depósitos lamosos anteriores são erodidos e às vezes transformados em clastos intraformacionais. A forte atividade erosiva durante o período de inverno limita a preservação de depósitos gerados por marés durante o verão e o registro sedimentar final deste sistema é dominado por sedimentos produzidos por ondas, embora a área corresponda a uma planície de maré (Yang et al. 2005). O modelo deposicional apresentado é caracterizado nas áreas mais distais por HCS do tipo de erosão e preenchimento (Cheel \& Leckie 1993) separados ás vezes por lâminas delgadas de lama. Da parte mais distal à parte mais proximal da costa as camadas com HCS diminuem de espaçamento e de espessura, sendo progressivamente substituídas por laminações plano-paralelas e marcas de onda. Só nas partes costeiras mais protegidas observam-se depósitos lamosos caracterizados por ritmitos, típicos de planície de maré.

O sistema deposicional da Formação Lagarto apresenta algumas similaridades com o modelo descrito. Ambos os sistemas apresentam uma interação entre processos deposicionais produzidos por ondas e marés, sem apresentar, entretanto, aspectos que caracterizem um sistema dominado integralmente por ondas ou marés. De fato em ambos os casos o registro da atividade das ondas é representado por depósitos de tempestade e secundariamente por marcas de onda, faltando estrutu- ras mais típicas de praia submersa superior (upper shoreface) e praia emersa (foreshore). Por enquanto a atividade das marés é representada por ritmitos de planície de maré, faltando estruturas maiores como depósitos de canais ou barra de maré.

Todavia, o sistema deposicional de Lagarto mostra vários aspectos que o diferenciam do modelo de planície de maré de costa aberta da baia de Baeksu. Todos os três elementos arquiteturais mostram indícios de emersão, que associados com a presença de camadas depositadas por marés podem ser atribuídos ás variações cíclicas do nível do mar ligadas provavelmente a ciclos de maré. Não temos dados para inferir a máxima amplitude da maré, mas em comparação com os sistemas deposicionais atuais análogos, relativos a costas abertas e sujeitas a ação das marés e das ondas (Li et al. 2000; Yang et al. 2005; 2008), podemos supor que este valor no período de sizígia fosse superior a 6 $\mathrm{m}$. De fato, os autores citados não observaram emersões nas áreas mais profundas onde se depositam HCS com grande espaçamento e espessura, enquanto que na Formação Lagarto estas evidências são claras. Esta alta variação da excursão das marés implica em uma alta influência dos efeitos das marés nos processos deposicionais. Efetivamente os depósitos originados por marés possuem na Formação Lagarto ampla difusão, maior que no modelo da baia de Baeksu. Os sub-elementos arquiteturais $2 \mathrm{a}$ e $\mathrm{b}$ possuem mais da metade da espessura dos depósitos originados por ou com influência das ma- 
rés, por enquanto o elemento 3 é quase completamente constituído por depósitos de maré. Isto diferencia o sistema deposicional da Formação Lagarto do modelo de Yang et al. (2005) e marca um maior peso da influência das marés nos processos deposicionais, em particular nas áreas intermediárias e proximais da costa. É provável que o maior controle das marés na construção do sistema deposicional tenha sido causado não só por uma alta excursão do nível do mar, como também por uma morfologia costeira com um baixo gradiente topográfico. Na baia de Baeksu os depósitos lamosos de marés (planície de maré interna) são mais comuns onde o gradiente topográfico costeiro é menor e onde a ação das ondas é reduzida por efeito do atrito com o fundo.

Portanto, conclui-se que a Formação de Lagarto é constituída por um sistema deposicional de costa aberta cuja sedimentação é dominada por ondas de tempestade na parte distal e mostra uma maior influência dos processos deposicionais controlados por marés se aproximando da costa.

Conservação de HCS em água rasas Geralmente, no registro geológico, os depósitos de tempestade não são preservados em sistemas deposicionais de água rasa (Yang \& Chun 2001; Yang et al. 2005). De fato, a presença de $H C S$ nas sucessões sedimentares é comumente associada a sistemas deposicionais de praia submersa inferior (lower shoreface) ou de plataforma (Reading 1996). Porém, trabalhos realizados em depósitos atuais costeiros ou de planície de maré aberta descrevem a deposição de areias com estruturas tipo HCS (Duke 1985; Greenwood \& Shermand 1986; Li et al. 2000; Yang \& Chun 2001; Yang et al. 2005, 2006, 2008). O grau de preservação destes depósitos arenosos, produzidos por ondas de tempestades, é todavia muito baixo, porque podem ser facilmente e rapidamente retrabalhados por correntes de maré, ondas de tempo bom (fair-weather waves) e destruídos pela atividade de organismos (bioturbação). Assim, mesmo que exista a formação de camadas de areia com estruturas tipo $H C S$ em água rasa, a possibilidade de preservação geológica destes depósitos é baixa. Contudo, se numa sucessão sedimentar de água rasa se encontram depósitos areníticos com $H C S$, isto significa que devem ser satisfeitas algumas condições que permitem a preservação. Estas condições são identificadas nas seguintes situações: (1) não devem existir processos físicos (ondas ou correntes de marés) de energia suficiente a retrabalhar os depósitos de tempestade; (2) não devem existir comunidades biológicas que destruam as estruturas sedimentares e a organização das camadas; (3) os sedimentos de tempestade devem ser rapidamente cobertos para permitir uma rápida inserção no registro geológico (Li et al. 2000; Fan et al. 2002).

Estas condições parecem ter sido satisfeitas durante a deposição da Formação Lagarto. (1) A área deposicional costeira onde se depositou a Formação Lagarto era uma área protegida das ondas de tempo bom e de fortes correntes de maré. Só grandes ondas de tempestade, provavelmente geradas por ciclones com periodicidade sazonal, podiam alcançar a área de intermaré, transportar e depositar areia de médio-fina a fina. Embora a excursão da maré fosse maior que $6 \mathrm{~m}$, não se geravam correntes na costa com suficiente velocidade para transportar areia e gerar estruturas morfo-deposicionais típicas de ambientes dominados pela influência da maré. A proteção da costa provavelmente era gerada por efeito de um gradiente topográfico muito baixo numa costa aberta que causava a progressiva diminuição da energia das ondas normais e das marés em direção da terra firme. Só tempestades de grande energia conseguiam alcançar as áreas mais internas da costa. Tais condições morfológicas da costa atuaram numa área relativamente extensa por um tempo relativamente longo, sendo que a Formação Lagarto se desenvolve com características deposicionais similares por mais de $1300 \mathrm{~m}$ em área de maior que $400 \mathrm{~km}^{2}$. (2) A Formação Lagarto, em prática, não contem restos fosseis ou traços de bioturbações. Foram encontradas só uma provável exúvia de trilobite, pertencente provavelmente à ordem Phacopida (Basilici et al. 2008) (Fig. 19A), ordem que se desenvolve a partir do Cambriano por todo o Ordoviciano, e estruturas atribuíveis a esteiras microbianas (MISS - microbially induced sedimentary structure) (Fig. 19B e C) (Bottjer $\&$ Hagadorn 2007; Renata G. Netto, comunicação pessoal, 2009). A idade da Formação Lagarto é inferior que 540MA, que é idade dos mais novos elementos detríticos de zircão encontrados nos arenitos (Oliveira 2008). Assim, a ausência de restos fósseis sensu strictu e de icnofósseis num período onde já se desenvolveram vários grupos de organismos é provavelmente explicável com condições ambientais críticas, onde a rarefação ou falta de organismos superiores podia permitir o desenvolvimento de esteiras bacterianas. A forte oscilação da maré e variáveis e/ou anômalas condições de salinidade geraram condições ambientais hostis à vida aquática e, consequentemente, inibiram a atividade de remanejamento dos sedimentos. (3) A Formação Lagarto possui as mesmas características sedimentológicas de área de intermaré por toda a sua espessura e extensão. Mesmo supondo que a excursão das marés fosse superior aos $10 \mathrm{~m}$, para a geração de uma espessura de sedimentos de intermaré desta ordem deve-se admitir que a bacia de sedimentação era sujeita a alta criação de espaço de acomodação que era acompanhada por um aporte de sedimento do mesmo volume. $\mathrm{O}$ aporte de sedimento era provavelmente alto como sugerido pela imaturidade física e química dos arenitos. Alta taxa de sedimentação é também testemunhada pelas características geotectônica da bacia, que é interpretada como uma bacia de antepaís (Oliveira 2008). Assim, também é provável que uma alta taxa de sedimentação contribuísse para a preservação geológica das HCS. A alta taxa de sedimentação seria também a causa de uma progradação e extensão da área costeira de intermaré, que teria produzido um perfil topográfico baixo atenuando a atividade de ondas e maré na direção da costa.

CONCLUSÕES A Formação Lagarto foi depositada num sistema costeiro aberto com influência mista de ondas e marés (open-coast tidal flat). Existem descri- 


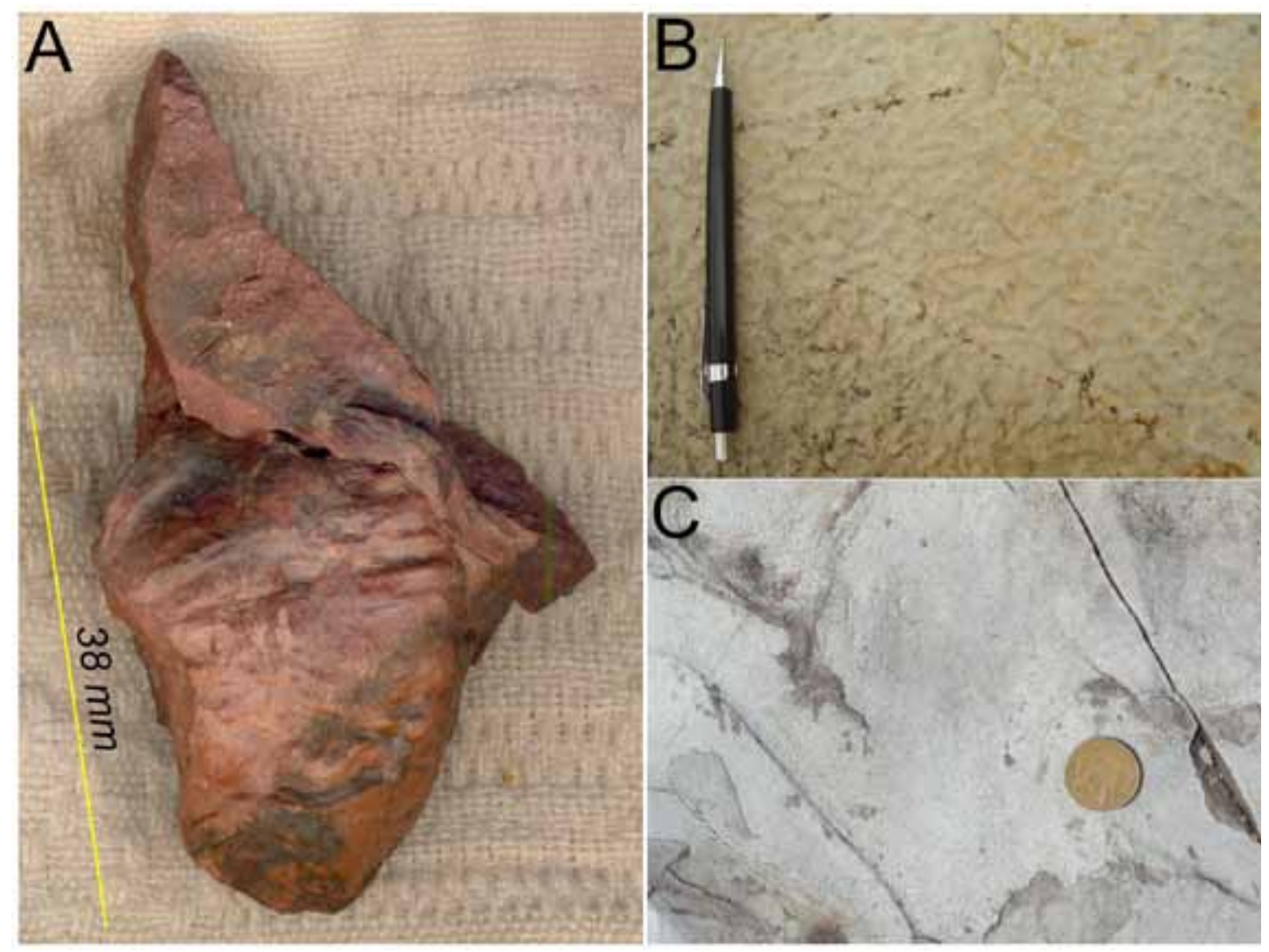

Figura 19 - Fósseis na Formação Lagarto. (A) Provável exúvia de trilobita pertencente à ordem Phacopida. (B) Deformação plástica por carga provocada numa superficie de areia muito fina por uma pelicula de esteira microbiana. Lapiseira: $143 \mathrm{~mm}$. (C) Estrutura chamada de "pele de elefante velho" devida à dessecação de esteiras microbianas numa superficie expostas ao ar. Moeda: $24 \mathrm{~mm}$.

ções de ambientes de sedimentação atuais deste tipo, mas sucessões sedimentares antigas com estas características são pouco conhecidas. Neste trabalho a Formação Lagarto é apresentada como o exemplo fóssil de um ambiente de costa aberta dominada por ondas. As principais conclusões são descritas a seguir.

(1) A Formação Lagarto foi subdividida em três elementos arquiteturais que são caracterizados por uma diferente distribuição em tipo e espessura de sete litofácies. O elemento 1 , que forma sucessões espessas até $60 \mathrm{~m}$, é caracterizado prevalentemente por camadas de HCS acrescionais (litofácies 1), interestratificadas com camadas de arenitos muito finos com marcas de ondas (litofácies 5). Este elemento é interpretado como depósito da área mais profunda de uma zona de intermaré ou da parte superior da zona de supramaré. O elemento 2 é formado por dois sub-elementos: $2 \mathrm{a}$ e $2 \mathrm{~b}$. O subelemento $2 \mathrm{a}$ forma sucessões entre 20 e $30 \mathrm{~m}$ espessas e é constituído prevalentemente por arenitos com marca de ondas e laminações plano-paralelas (litofácies 5), interestratificados com camadas de $H C S$ do tipo erosão e preenchimento (scour and drape HCS) (litofácies 2), estratificações cruzadas (litofácies 4) e pelitos (litofácies 6). O sub-elemento $2 \mathrm{~b}$ é constituído camadas de arenito, que mostram $H C S$ de tipo migratório (litofácies 3) e marcas de ondas (litofácies 5), interestratificadas com pelitos (litofácies 6). O elemento 2 é interpreta- do com produto de deposição em área de intermaré. O elemento 3 forma pacotes com espessura maior que $200 \mathrm{~m}$, caracterizados por pelitos laminados (litofácies 7), raramente interestratificados com camadas amalgamadas de arenitos com HCS migratórias (litofácies 3 ). Este elemento é interpretado como porção superior de uma área de intermaré.

(2) Os três elementos possuem por cerca de 1300 $\mathrm{m}$ de espessura uma distribuição homogênea e as litofácies que os constituem foram geradas por processos sedimentares físicos similares. Por estas razões foi admitido que eles fossem parte do mesmo sistema deposicional. A posição de distalidade ou proximalidade dos três elementos, com relação à linha de costa, foi definida em base à relação da espessura de arenito/pelito e distribuição dos processos deposicionais, deduzidos a partir da análise de fácies. A espessura das camadas areníticas diminui progressivamente passando do elemento $1,2 \mathrm{a}, 2 \mathrm{~b}$ até o 3 . A relação arenito/pelito varia respectivamente de 99,5 , 3,5 até 0,25 . Do elemento 1 até o 3 observa-se, de forma progressiva, uma menor influência dos fluxos ligados às tempestades e um aumento da influência de correntes de marés na deposição de material mais fino. Assim, o elemento 1 é interpretado como o elemento mais distal e os elementos $2 a, 2 b$ e 3 são, nesta ordem, localizados sempre mais perto da costa.

(3) O sistema deposicional da Formação Lagar- 
to é um sistema deposicional híbrido caracterizado pela influência de ondas, principalmente de tempestade, e de maré e pode ser comparado a um sistema costeiro aberto de planície de maré (open-coast tidal flat), sujeito a periódicas, provavelmente sazonais, atividade de ondas de tempestade. O efeito de proteção da ação das ondas de tempo bom e das correntes de marés era provavelmente devido a uma planície de maré extensa e de muito baixo gradiente topográfico, que causava a progressiva perda de energia de ondas e marés por atrito da lâmina de água com o fundo. Só as fortes ondas de tempestades podiam alcançar a área de intermaré e depositar arenitos com estruturas de $H C S$.

(5) A Formação Lagarto é um dos poucos casos citados em literatura no qual $H C S$ de baixa profundidade de lâmina de água são preservadas no registro geológico. Acredita-se que três fatores tenham permitido esta ocorrência. Primeiro, a ausência de processos físicos que após a tempestade podiam ter retrabalhado os depósitos com HCS. De fato, as ondas de tempo bom conseguiram só retrabalhar a porção superior das camadas com $H C S$ ou depositar sedimentos em forma de marcas de ondas e as correntes de maré em geral só tinham energia para transportar lama e areia muito fina. Segundo, as condições paleoambientais desfavoráveis à vida de uma rica comunidade biológica. Consequentemente, as camadas com $H C S$ não foram destruídas por bioturbação. Terceiro, um rápido soterramento das camadas. A bacia onde se depositou a Formação Lagarto é interpretada como uma bacia de antepaís sujeita a alta criação de espaço de acomodação por flexura da crosta continental e alto aporte de sedimento pela presença de uma cadeia orogênica em formação (a Faixa Sergipana). A grande espessura e monotonia desta formação e a imaturidade dos seus sedimentos areníticos sugerem efetivamente que a construção desta unidade ocorreu com uma alta taxa de sedimentação.

Agradecimentos À FAPESP projeto 2006/00525-2 e ao CNPq, processo 473356/2007-4. A Renata G. Netto pela interpretação das estruturas produzidas pelas esteiras microbianas. Agradecemos, em fim, o/a anônimo/a parecerista e Ernesto Lavina pelos interessantes comentários ao manuscrito.

\section{Referências}

Allen J.R.L. 1982. Sedimentary Structures: their character and physical basis. Amsterdam, Elsevier, 663 p.

Basilici G., De Luca P.H.V., Ghilardi R. 2008. Anatomy of an Ordovician or Devonian (?) shallow-water storm-dominated tidal open coast: the Lagarto Formation, Sergipano Belt. In: Workshop Sobre a Geologia do Pré-Cambriano da Província Borborema, Unicamp/Campinas, Resumos, p. 16-17.

Bottjer D. \& Hagadorn J.W. 2007. Mat growth features. In: Schieber J., Bose P.K., Eriksson P.G., Banerjee S., Altermann W., Catuneau O. (eds.) Atlas of mat features preserved within the clastic rock record. Elsevier, p.: 53-71.

Boyd R., Dalrymple R.W., Zaitlin B.A. 1992. Classification of clastic coastal depositional environments. Sed. Geol., 80:139-150.

Brenchley P.J. \& Newall G. 1982. Storm-influenced inner-shelf sand lobes in the Caradoc (Ordovician) of Shropshire, England. Journal of Sedimentary Petrology, 52:1257-1269.

Brenchley P.J. 1985. Storm influenced sandstone beds. Modern Geology, 9:369-396.

Cheel R.J. \& Leckie D.A. 1993 Hummocky cross-stratification. In: Wright V.P. (ed.) Sedimentology Review. Oxford, Blackwell Science, 1:103-122 .

Craft R.J. \& Bridge J.S. 1987. Shallow-marine sedimentary processes in the Late Devonian Catskill Sea, New York State. Geol. Soc. Am. Bull., 98:338-355.

D'el-Rey Silva L.J.H. 1995, Tectonic evolution of the Sergipano Belt, NE Brazil. Revista Brasileira de Geociências, 25:315-332.

Dalrymple R.W., Yang B.C., Chun S.S. 2006. Sedimentation on a wave-dominated, opencoast tidal fl at, south-western Korea: Summer tidal fl at-winter shoreface-Reply. Sedimentology, 53:693-696.

Dalrymple R.W., Zaitlin B.A., Boyd R. 1992. Estuarine facies models: conceptual basis and stratigraphic implications. $J$. Sed. Petrol., 62:1130-1146.

Davis Jr. R.A. \& Fitzgerald D.M. 2004. Beaches and Coasts. Malden, Blackwell Publishing, 419 p.

De Luca P.H.V. 2008. Modelo de distribuição de depósitos areníticos em sistemas análogos de plataforma marinha: um exemplo do Cambriano da Faixa Sergipana (Formações Lagarto e zPalmares, Domínio Estância, Sergipe e Bahia). Dissertação de Mestrado, Departamento de Engenharia de Petrólio, Unicamp, 90 p.

De Raaf J.F.M., Boersma J.R., Van Gelder A. (1977) Wavegenerated structures and sequences from a shallow marine succession, Lower Carboniferous, County Cork, Ireland. Sedimentology, 24:451-483.

Dott R.H.Jr. \& Bourgeois J. 1982. Hummocky stratification: Significance of its variable bedding sequences. Geological Society of America, Bulletin, 93:663-680.

Duke W.L. 1985. Hummocky cross-stratification, tropical hurricanes, and intense winter storms. Sedimentology, 32:167194.

Dumas S., Arnott R.W.C., Southard J.B. 2005. Experiments on oscillatory-flow and combined-flow bed forms: implications for interpreting parts of the shallow-marine sedimentary record. Journal of Sedimentary Research, 75:501-513.

Fan D.D., Li C.X., Archer A.W., Wang P. 2002. Temporal distribution of diastems in deposits of an open-coast tidal-flat with high suspended sediment concentrations: Sedimentary Geology, 152:173-181.

Fan D.D., Li C.X., Wang P. 2004. Influences of storm erosion and deposition on rhythmites of the upper Wenchang Formation (Upper Ordovician) around Tonglu, Zhejiang Porovince, China. Journal of Sedimentary Research, 74:527536.

Greenwood B. \& Sherman J. 1986. Hummocky cross-stratifi- 
cation in the surf zone: flow parameters and bedding genesis. Sedimentology, 33:33-45.

Ito M., Nishikawa T., Saito T. 2001. Temporal variation in the wavelength of hummocky cross-stratification: Implications for storm intensity through Mesozoic and Cenozoic. Geology, 29:87-89.

Jopling A.V. \& Walker R.G., 1968. Morphology and origin of ripple-drift cross-lamination, with examples from the Pleistocene of Massachusetts. Journal of Sedimentary Petrology, 47:697-706.

Kim B.O. 2003. Tidal modulation of storm waves on a macrotidal flat in a Yellow Sea: Gomso Bay, Korea. Estuarine, Coastal and Shelf Sciences, 57:411-420.

Lanier W. \& Tessier B. 1998. Climbing-ripples bedding in the fluvio-estuarine transition: a common feature associated with tidal dynamics (modern and ancient analogues). In: Alexander C.R., Davis R.A., Henry V.J. (eds.) Tidalites: processes and products. SEPM, Special Publication, 61:109-117.

Le Hir P., Roberts W., Cazaoillet O., Christie M., Bassoullet P., Bacher C. 2000. Characterization of intertidal flat hydrodynamics. Continental Shelf Research, 20:1433-1459.

Li C., Wang P., Fan D., Bing D., Li T. 2000. Open-coast intertidal deposits and the preservation potential of individual laminae: a case study from east-central China. Sedimentology, 47:1039-1051.

Mutti E. 1992. Turbidite sandstone. Milano, Agip Spa, 275 p.

Myrow P.M. \& Southard J.B. 1991. Combined flow model for vertical stratification sequences in shallow marine stormdeposited beds. Jl. of Sedimentary Petrology, 61:202-210.

Myrow P.M. 1992. Bypass-zone tempestite facies model and proximality trends for an ancient muddy shoreline and shelf. Journal of Sedimentary Research, 62:99-115.

Myrow P.M., Fischer W., Goodge J.W. 2002. Wave-modified turbidites: combined-flow shoreline and shelf deposits, Cambrian, Antartica. Journal of Sedimentary Research, 72:641-656.

Oliveira E.P. 2008 Evolução geológica da Faixa Sergipana, limite sul da Província Borborema. In: Workshop Sobre a Geologia do Pré-Cambriano da Província Borborema, Resumos das Apresentações, Unicamp-Campinas, p. 14-15.

Pettijohn P.J., Potter P.E., Siever R. 1987. Sand and Sandstone. New York, Springer-Verlag, 553 p.

Reading H.G. 1996. Sedimentary Environments: Processes, Facies and Stratigraphy. Oxford, Blackwell Science, 688 p.

Reineck H.E. \& Singh I.B. 1980. Depositional Sedimentary Environments. 2a Ed., New York, NY, USA, SpringerVerlag, $439 \mathrm{p}$.

Saes G.S. \& Vila Boas G.S. 1983. Fácies sedimentares da Formação Lagarto, Pré-Cambriano superior no extremo nordeste da Bahia. Revista Brasileira de Geociências, 13:263270.

Saes G.S. \& Vila Boas G.S. 1986. Fácies sedimentares e modelos de sedimentação da Formação Acauã. Pré-Cambriano Superior no nordeste da Bahia. Revista Brasileira de Geociências, 16:263-270.

Saes G.S. \& Vila Boas G.S. 1989. Depósitos de leque costeiros (Fan Deltas) e de plataforma marinha rasa do Grupo Estância, Proterozóico Superior (Bahia, Sergipe). Revista Brasileira de Geociências, 19:343-349.
Saes G.S. 1984. Estratigrafia e sedimentologia do Grupo Estância na região nordeste do Estado da Bahia. Salvador, Dissertação de Mestrado, UFBA, 107 p.

Santos R.A., Martins A.A.M., Neves J.P., Leal R.A. 1998. Geologia e recursos minerais do estado de Sergipe. Texto explicativo do mapa geológico do estado de Sergipe. CPRM, $156 \mathrm{p}$.

Seilacher A. \& Aigner T. 1991. Storm Deposition at the Bed, Facies, and Basin Scale: the Geologic Perspective. In: Einsele G., Werner R., Seilacher A. (eds.) Cycles and Events in Stratigraphy. Berlin Heidelberg, Springer-Verlag, p. 249-267.

Silva Filho M.A., Bomfim L.F.C., Santos R.A. 1978a. A geossinclinal Sergipana: estratigrafia, estrutura e evolução. In: Congresso Brasileiro de Geologia, 30, Recife, Anais, p. 2464-2477.

Silva Filho M.A., Bomfim L.F.C., Santos R.A. 1978b. Evolução tectono-sedimentar do grupo Estância: suas correlações. In: Congresso Brasileiro de Geologia, 30, Recife, Anais, p. 685-699.

Tessier B. 1993. Upper intertidal rythmites in the Mont-St-Michel Bay (NW France): perspectives for paleoreconstruction. Marine Geology, 110: 355-367.

Tessier B. 1998. Tidal cycles: annual versus semi-lunar records. In: Alexander C.R., Davis R.A., Henry V.J. (eds.) Tidalites: Processes and products. SEPM (Society for Sedimentary Geology) Special Publication 61:69-74.

Tessier B., Archer A.W., Lanier W.P., Feldman H.R. 1995. Comparison of Ancient tidal rhythmites (Carboniferous of Kansas and Indiana, USA) with Modern analogues (the Bay of Mont-Saint-Michel, France). Special Publication of the International Association of Sedimentologists 24:259271.

Walker R.G. 1984. Shelf and shallow marine sands. In: Walker R.G. (ed.) Facies Models. 2nd Edition, Geoscience Canada, Reprint Series, 1:141-170.

Walker R.G. 2006. Facies models revisited: Introduction. In: Posamentier H.W. \& Walker R.G. (eds.) Facies models revisited, SEPM Spec. Publ., 84:1-17.

Yang B.C. \& Chun S.S. 2001. A seasonal model of surface sedimentation on the Baeksu open-coast intertidal flat, southwestern coast of Korea. Geosci. J., 5:251-262.

Yang B.C., Dalrymple R.W., Chun S.S. 2005. Sedimentation on a wave-dominated, open coast tidal flat, south-western Korea: summer tidal-flat - winter shoreface. Sedimentology, 52:235-252.

Yang B.C., Dalrymple R.W., Chun S.S. 2006. The significance of hummocky cross-stratification $(H C S)$ wavelenghts: evidence from an open-coast tidal flat, South Korea. Journal of Sedimentary Research, 76:2-8.

Yang B.C., Gingras M.K., Pemberton S.G., Dalrymple R.W. 2008. Wave-generated tidal bundles as an indicator of wave-dominated tidal flats. Geology, 36:39-42

Yokokawa M., Masuda F., Endo N. 1995, Sand particle movement on migrating combined-flow ripples: Journal of Sedimentary Research, 65:40-44.

Manuscrito ID 15347

Submetido em 11 de setembro de 2009 Aceito em 05 de julho de 2010 